\title{
Viewing Health as a Human Right: \\ On the Normative Framework Linking Health to \\ Human Rights
}

by

Darlene Drecun

A thesis submitted to the Faculty of Graduate and Postdoctoral Affairs in partial fulfillment of the requirements for the degree of

Master of Arts

in

Philosophy

Carleton University

Ottawa, Ontario

(C) 2013, Darlene Drecun 


\begin{abstract}
The current global health literature is skeptical of the idea that one can defensibly claim a moral right to health. Gopal Sreenivasan and Onora O'Neill argue that a positive right to health is fraught with conceptual difficulties because it is unclear who bears the correlative duty to secure the right. Jonathan Wolff has recently attempted to provide a normative foundation for the human right to health from a non-cosmopolitan point of view, but his account fails to directly address Sreenivasan and O’Neill's objections. In this paper, I will develop and further substantiate Wolff's position in an attempt to respond to Sreenivasan and O'Neill's critique of a positive right to health. I will argue that Wolff unknowingly seems to be making a case for a negative right to health, which I conclude provides a non-cosmopolitan normative foundation for the human right to health.
\end{abstract}




\section{Acknowledgements}

This project would not have been possible without the support of many people. Many thanks to my supervisor, Dr. Vida Panitch, who introduced me to the topic of health rights, read my numerous revisions and supported me through the process of my master's thesis. Also, I would like to thank Dr. Jay Drydyk for his support along the way. I would finally like to thank my parents, Novak and Rebeca Drecun, my colleague and partner Zachary Fouchard, my friend and favorite editor Kimberley Mercer-Lynn, and my other family members and friends who have supported me throughout the entire process. 


\section{Table of Contents}

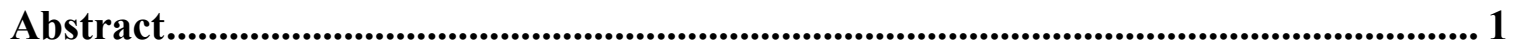

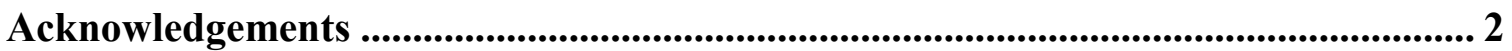

Table of Contents .............................................................................................................. 3

1 Chapter: Viewing Health as a Human Right ................................................................ 5

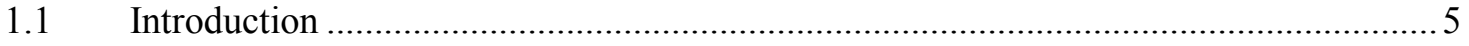

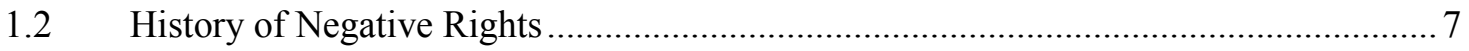

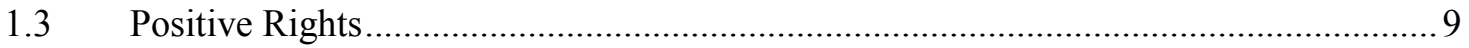

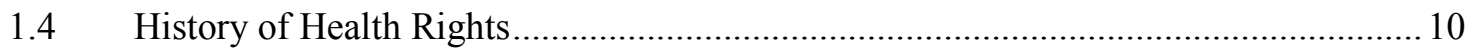

1.5 Criticisms of the Human Right to Health: Sreenivasan and O'Neill's Objections....... 14

1.6 Concerns and Misunderstandings in the Human Right to Health Debate ....................21

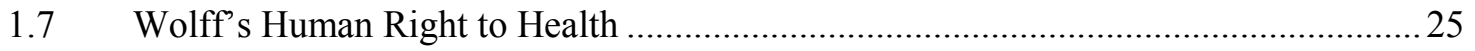

1.8 Identifying a Duty Bearer: Developing Wolff's Claims as a Possible Response to

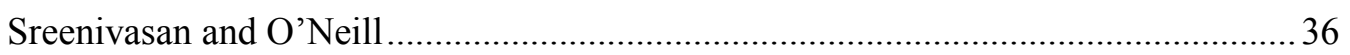

1.9 Cosmopolitanism and Wolff's Health as a Human Right Position ................................ 38

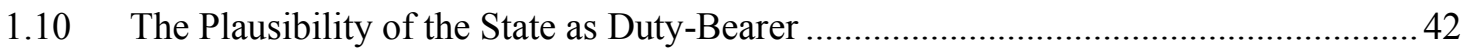

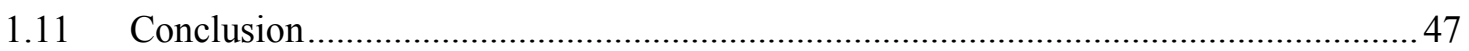

2 Chapter: Literature Review........................................................................................... 50

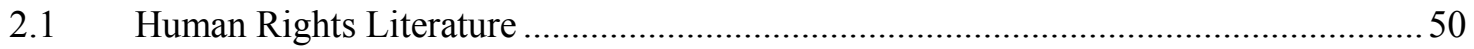

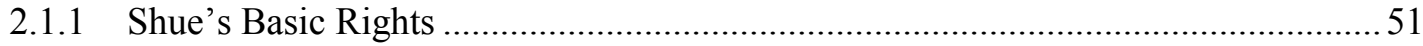

2.1.2 Shue's Institutional Approach to Human Rights and their Corresponding Duties ...53

2.1.3 Beitz's Two-Level Model of Human Rights............................................................ 55

2.1.4 Human Rights Doctrine: UN Declarations and Covenants......................................58

2.2 Proponents of the Human Right to Health Approach.................................................60

2.2.1 Mann's Health and Human Rights Three-Part Framework .....................................60

2.2.2 Farmer's First-Hand Accounts of Health and Human Rights ................................... 61 
2.2.3 Wolff's Philosophical Account of the Human Right to Health Approach.

2.3 Critics of the Human Right to Health Approach ................................................... 70

2.3.1 Sreenivasan's Argument from the Nature of Health................................................. 71

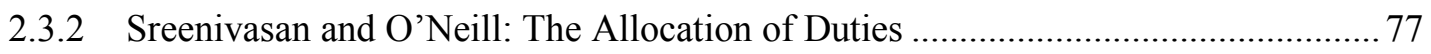

2.3.3 Fenton and Arras: The Resource Allocation Problem ........................................... 80

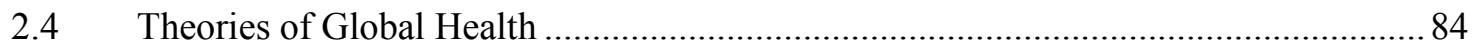

2.4.1 Buchanan and Hessler: Specifying the Content of a Human Right to Health Care .. 85

2.4.2 Buchanan and Matthew Decamp: Responsibility for Global Health ........................ 89

2.4.3 Norman Daniels: Normal Opportunity Range in Health ........................................ 91

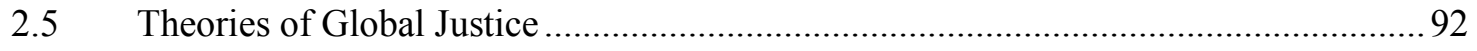

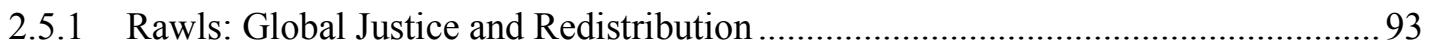

2.5.2 Pogge: The Global Resource Dividend and the Health Impact Fund .......................97

2.5.3 Sen and Nussbaum: The Capabilities Approach and Health Rights ........................ 102

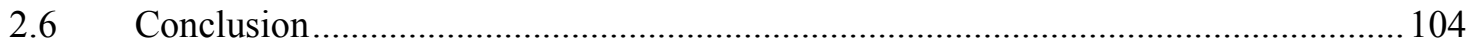

Bibliography ....................................................................................................................... 106 


\section{Chapter: Viewing Health as a Human Right}

\subsection{Introduction}

"So I can't show you how, exactly, health care is a basic human right. But what I can argue is that no one should have to die of a disease that is treatable."

Dr. Paul Farmer

As medical innovation has progressed, many illnesses have become treatable and in some cases, even completely eradicated from parts of the world. Farmer's quote refers to the painful injustice that occurs when millions of people die because they were unable to afford lifesaving medication, or were not lucky enough to have been born in an area of the world with access to clean water and nutritious food. Instead, for Farmer, health as a human right is clearly demonstrated everyday as he witnesses the injustice of those dying from treatable diseases because they do not have this right secured. The quote also shows the difficulty in articulating how, exactly, health is a human right. However, as difficult as justifying the concept of health as a human right may be, does not mean that it is impossible.

Although a legal human right to health has been established in international law for decades (ICSECR, 1976), the question of whether a moral right to health exists is still heavily debated in political philosophy. A moral human right to health must be philosophically justified to be considered more than an aspirational statement. Current literature on the right to health has been extremely critical of the idea that we can defensibly claim a moral right to health. In particular, Gopal Sreenivasan (2012) and Onora O’Neill (2005) have raised powerful objections against the existence of the 
concept of a right to health. Sreenivasan and O'Neill take the human right to health to be a positive right, following the drafters of the UN Declaration of Human Rights. Their main concern with a positive human right to health is that the right is without substance because it fails to identify a duty-bearer; thus there is no duty to fulfill the right to health. Jonathan Wolff (2012) has recently attempted to provide a normative foundation for the human right to health approach; however, he has not fully addressed Sreenivasan and O'Neill's objections. Wolff offers the most compelling case for the human right to health; yet, he has not articulated his view clearly and as a result, others responding to his arguments and those to whom his argument is presumably addressed have not realized what his approach is trying to do. In this paper I will be developing and further substantiating Wolff's claims. If properly understood and developed, it can provide the right type of response against Sreenivasan and O'Neill's main objections. The responses Wolff offers explicitly are weak and seem to ignore the central problem in the debate. However, the fundamental idea in his view provides the crucial component that clarifies the problem; it is this point that I will develop into a plausible response to the key normative objections to a human right to health.

The first three sections outline the historical development of human rights: distinguishing between negative and positive rights, and showing the development of the concept of the human right to health. Following this, I will discuss Sreenivasan and O'Neill's two most damaging objections to the human right to health approach. Although Wolff does not seem to realize it, he clearly understands the human right to health as a negative right, not a positive right. Therefore Wolff's approach, with some development, can provide an adequate response to Sreenivasan and O'Neill's critique of 
the human right to health by avoiding the main objection they launch at a positive right to health. This objection is also clearly directed at cosmopolitans and I will demonstrate that Wolff's claims are not grounded in a cosmopolitan justification.

\subsection{History of Negative Rights}

The notion of a human right can be traced back to enlightenment era discussions of natural rights. Locke was one major proponent of the idea of rights. In a time period when humans were merely powerless subjects to their sovereign, Locke claimed that man had natural rights to "life, liberty and estate" (Locke, Two Treatises of Government). Instead of the sovereign holding absolute power over the people, Locke argued that governments were given power through a social contract with the people. However, governments must guarantee certain rights to its citizens in order to gain their legitimacy. If these rights were violated, the people would have a right to legitimately rebel. The social contract and rights to life, liberty and property serve as foundations for many contemporary liberal democracies today. The American Declaration of Independence, largely formulated by Thomas Jefferson and greatly inspired by Locke, famously states:

We hold these truths to be self-evident, that all men are created equal, that they are endowed by their Creator with certain inalienable Rights, that among these are Life, Liberty and the pursuit of Happiness (Declaration of Independence, 1776).

The French Declaration also mentions inalienable rights of man that are born free and equal. This conception of rights shaped what we currently know as civil and political rights. After the Civil War in the United States in the late 1800's, civil rights began to 
develop (Edmundson 2004, 32). Newly emancipated slaves were granted rights, such as property rights, participation in the political process and due process.

This time period also saw a rise in the popularity of Utilitarianism. John Stuart Mill's Utilitarianism directly impacted the way we have come to think of liberty rights, particularly his "harm principle." Mill's conception of liberty rights was that people had the right to follow their own life plans and ideas of happiness, as long as their actions did not harm any others (Mill, On Liberty). Mill's harm principle is a fundamental aspect to today's civil and political rights, which are based on the idea of non-interference. That is, people have negative civil and political rights of non-interference, which are often described as refrainment from an action. An example of this would be not engaging in certain actions that would infringe on another's civil or political rights. Negative rights are to be protected and respected by all persons universally.

With the advent of post-World War II discussions about how to avoid the atrocities experienced during the war from ever occurring again, the term "human rights" was coined, and the previous rights articulated by Locke and Mill were recognized internationally. The creation of the Universal Declaration of Human Rights, adopted by the UN General Assembly on December 10, 1948, covered protection against discrimination, including race, color, sex, language, religion, political opinion, property, and birth or other status (Article 2). The Declaration covered what would later become termed "first-generation" rights, such as rights to religion, opinion, thought and expression, to assemble and to associate; to participate in free elections and access to public office (Articles 18-21). 


\subsection{Positive Rights}

Although the focus of the Universal Declaration of Human Rights was on negative rights, positive rights were also introduced in the Declaration. In contrast to negative rights that are generally thought of as a refrainment of action, positive rights, or second-generation rights, correspond with duties that are acts of assistance. Some rights require more than just not harming another; they involve positive actions in order to help secure another's right.

Articles 22-30 of the Universal Declaration of Human Rights listed second generation, positive rights, such as: the right to social security to be enjoyed by everyone, just and favorable working conditions, protection against unemployment, equal pay for equal work, and the right to join a union (Article 23). Articles 25 and 26 specifically set out many of the positive rights that we think of today as minimum needs for a decent life such as: the right to an adequate standard of living including food, clothing, housing and medical and necessary social services (Article 25) and the right to free education (Article 26).

As significant as the Universal Declaration of Human Rights was, binding covenants were needed in order for countries to sign on and commit to the newly created international human rights laws. After several drafts, in 1976 the International Covenant on Civil and Political Rights (ICCPR) was established. Most countries ratified this agreement that sought to protect individuals from discrimination and persecution (OHCHR).

The second covenant created at this time was much more controversial. The International Covenant on Economic, Social, and Cultural Rights (ICESCR) was a 
significant achievement in positive rights. The international community for the first time was promoting the idea that they, along with governments, had more than just a duty to not violate civil and political rights, they also had the duty to assist those in need. Social goods and services were recognized for the important role they play in maintaining the lives of many in need. Unfortunately, the ICESCR was, and still is, quite contentious and has still to this day not been ratified by many countries (OHCHR).

\subsection{History of Health Rights}

The human right to health developed out of the advancement of social, economic, and cultural rights after World War II. The Declaration of Geneva was created and adopted by the General Assembly of the World Medical Association at Geneva in 1948 as a 'declaration of physicians' dedication to the humanitarian goals of medicine, a declaration that was especially important in view of the medical crimes committed in Nazi Germany" (World Medical Association). The idea that there was a moral duty to protect the health of all people was beginning to take shape. The World Health Organization was also created during this time period, stating its objective as:

The enjoyment of the highest attainable standard of health is one of the fundamental rights of every human being without distinction of race, religion, political belief, economic or social condition (Constitution of the WHO, 1946).

Along with other social and economic rights, the human right to health gained some force in international law by its inclusion in the ICESCR. Article 12 of this covenant states, "The States parties to the present Covenant recognize the right of 
everyone to the enjoyment of the highest attainable standard of physical health" (ICESCR Article 12). The right to health, as drafted in the Declarations and Covenants has been heavily criticized for being unrealistic and unattainable. The difficulty in determining a common standard of health, and the highest attainable standard of health is just one problem with the Covenant. Another serious issue with the Covenant is that it is extremely difficult for the international community to deal with a well-intentioned country that does not have the resources to fully realize the right to health for their citizens. In order to address this problem, the ISESCR includes a discussion of the progressive realization of rights. Rather than expecting a nation to be able to fulfill rights immediately, it is expected to use all of the resources they do have to work toward the eventual fulfillment of health rights. This notion was refined in 2000, when the Committee on Economic, Social and Cultural Rights issued General Comment 14.

30. While the Covenant provides for progressive realization and acknowledges the constraints due to the limits of available resources, it also imposes on States parties various obligations which are of immediate effect. States parties have immediate obligations in relation to the right to health, such as the guarantee that the right will be exercised without discrimination of any kind (article 2.2) and the obligation to take steps (article 2.1) towards the full realization of article 12. Such steps must be deliberate, concrete and targeted towards the full realization of the right to health. (UNHCHR General Comment 14, 2000)

Thomas Pogge is one political philosopher who has been trying to make us aware for some time of the dismal statistics about living in poverty and the impact poverty has on health, stating: 
Some 18 million human beings avoidably die each year from diseases we can prevent, cure, or treat... This huge incidence of mortality and morbidity is not randomly distributed. For a variety of social reasons, people of color and children are heavily overrepresented among those suffering severe ill health—and, within these categories, women and girls in particular (Pogge 2008, 222-23).

The World Health Organization has reported that in 2010, about 800 women die every day of pregnancy and child-birth-related complications. Of these 800 women, only five of them occurred in high-income countries. "The risk of a woman in a developing country dying from a pregnancy-related cause during her lifetime is about 25 times higher compared to a woman living in a developed country" (WHO 2012). The statistics regarding children's health is equally dire, with 6.9 million children dying by their fifth birthday in 2010 . " $58 \%$ of under-five deaths were caused by infectious diseases; Pneumonia, diarrhea and malaria accounted for more than one third of all under-five deaths in 2010" (WHO 2012). What stands out most about all of those deaths is how treatable most of them are if doctors and antibiotics are accessible. When it comes to those suffering from HIV, Sub-Saharan Africa continues to be the most heavily burdened by the epidemic. In Sub-Saharan Africa, "nearly 1 in every 20 adults (4.9\%) is living with HIV and account for 69\% of the people living with HIV worldwide" (WHO 2012).

Dr. Paul Farmer (1999) and the late Dr. Jonathan Mann (1998), respectively, have also extensively promoted the idea of health as a human right as a moral basis from which to criticize the global health inequalities Pogge highlights. Their focus is on government discrimination and the violation of human rights and the resulting negative effect this has on health. 
Mann discussed the relationship between human rights and health and used a three-part framework to demonstrate how they are linked. The first relationship shows the impact that health policies have on human rights. The construction of policies often impact oppressed groups and minorities, and at times can be highly racialized. The second relationship is that human rights violations often have a direct impact on health. Violations of political and civil rights often have a direct negative impact on the physical, mental and social well-being of all individuals affected. And finally, the third relationship restates that the promotion and protection of health is fundamentally linked to human rights (Mann, et al. 1999, 11).

Farmer bases his approach on his years of research and work through his own organization, Partners in Health (PIH), in Boston, Haiti, Peru and Russia. He has written numerous books documenting the massive health injustices occurring globally. On a daily basis, he witnessed a first-hand account of the poor suffering and dying from preventable diseases. His research has shown that diseases easily cross national borders, yet access to medications is radically different from country to country.

The study of borders qua borders means, increasingly, the study of social inequalities. Many political borders serve as semipermeable membranes, often quite open to diseases and yet closed to the free movement of cures. Thus may inequalities of access be created or buttressed at borders, even when pathogens cannot be so contained (Farmer 1996, 266).

As a doctor attempting to treat the ill in some of the poorest nations, Farmer's work pulls together first-hand accounts with years of medical and anthropological research to demonstrate the need for the human right to health. Farmer views state power as a potential cause of disease. Those suffering from illness and in desperate need of 
secured health rights are most often the same people that the state oppresses. These are also the most at risk for human rights violations. Farmer's approach is centered on the idea that most violations are rooted in "structural violence" - that is, social and economic inequalities determine who is subjected to rights violations (Farmer 1999, 1488).

\subsection{Criticisms of the Human Right to Health: Sreenivasan and O'Neill's}

\section{Objections}

All of the first-hand stories we hear about from people working in developing countries like Farmer make the scary health statistics much more real. We should care about the human right to health, because people that do not have this right are suffering immensely. However, the concept of a human right to health seems problematic for most philosophers.

Many have criticized the use of "the highest attainable standard of physical and mental health" in the Covenant (ICESCR, Article 12.1). It is questionable how such a grand declaration could realistically be guaranteed to everyone in the world when there are very serious problems in securing these rights in most areas of the world. This is why many consider Article 12 of the ISESCR hyperbolic, rather than an actual realistic standard.

It is debatable that we can even achieve a common standard of health across all borders, especially the highest attainable standard. It is common in cosmopolitan justifications of human rights approaches to attempt to justify a common standard of health for every global citizen. This is because cosmopolitans believe that there is one universal moral standard for all individuals. Furthermore, for cosmopolitans, national 
borders are completely arbitrary and should not be able to dictate an individual's quality of life. In terms of the human right to health, cosmopolitanism can be considered quite demanding; if citizens of one country have access to the highest attainable standard of health, then citizens of all other countries should also be guaranteed the same standard.

These are all problems that are raised against the human right to health; however, I will focus on what seems to be the most damaging objections to the human right to health from a philosophical standpoint, as articulated by Gopal Sreenivasan (2012) and Onora O'Neill (2005). The objections focus on the lack of a normative foundation in the human right to health approach. Sreenivasan and O’Neill both claim that we cannot identify whose duty it is to secure the human right to health. Without an identifiable duty-bearer, the human right to health is incoherent. As it stands, a positive right to health cannot be considered to have any normative justification.

These objections are very serious and damaging to the human right to health approach, and they have not been adequately addressed. As I will show later, even Wolff, who seems to be providing the philosophical counterpoint in the literature, nonetheless seems to explicitly ignore or sidestep these issues. There is a strong need for a philosophically justified account of this view. No one has provided a solid normative foundation for the human right to health approach, so as it stands, Sreenivasan and O'Neill's objections appear decisive. Without a proper foundation, the human right to health does not conceptually hold against its many objections. I hope to be able to provide this stronger normative foundation in my later sections through my development of Wolff's claims. 
Sreenivasan and O'Neill approach the subject quite differently, but seem to have very similar issues with establishing a right to health. O'Neill's critique of the human right to health is based on the distinction between negative and positive rights discussed in the first section of this paper. For O'Neill, this distinction creates two categories of rights: those for whom a duty-bearer of the right can be coherently identified, and those for whom one cannot. She distinguishes between "liberty rights," negative rights which she claims generate universal first-order duties, and positive rights to goods and services which at best produces second-order “special” duties (O’Neill 2005, 431).

It is much more difficult to identify duty-bearers connected to this type of right. Both liberty rights and rights to goods and services are seen as claims that are valid against those who hold the corresponding obligations. O’Neill emphasizes that the notion of a right is empty unless it is possible to identify the obligation-holder of that right. According to O'Neill there cannot be a right claim that is directed at no one or nobody in particular. In light of this, she points out that liberty rights are valid against everyone. Everyone has the duty to not interfere with others and to respect their liberty rights, and it is in this sense that liberty rights can be truly considered to be universal human rights.

In contrast to liberty rights, it is unclear whose duty it is to secure rights to goods and services. O'Neill claims that these types of rights require institutions in order to attempt to fulfill the claims. This distinguishes them from the pre-institutional universal human rights that fall under the category of liberty rights. If rights to goods and services are institutional, or "special rights," as she calls them, then they cannot be considered to be "possessed by all human beings simply in virtue of their humanity" (Beitz 2009, 49), 
as they require institutions in order to exist. According to O'Neill, universal rights are rights against everyone and special rights are rights against specifiable others (O'Neill 2005, 431). Therefore O'Neill claims that rights to goods and services cannot be considered to be universal human rights.

One possibility offered by $\mathrm{O}^{\prime}$ Neill is to consider human rights to goods and services as merely aspirational (O’Neill 2005, 430). In this sense we can eliminate the need for securing corresponding obligations, however we must sacrifice the human right as being anything more than just an unfulfilled demand and instead as an ideal toward which we should strive. Despite an acceptability of the notion of progressive rights in General Comment 14, O’Neill states that an aspirational view is not something proponents of human rights would want to accept. She claims that human rights are supposed to be prescriptive, not merely empty promises. In order for them to keep their normative qualities, they must be action guiding for some or all potential obligationbearers.

A normative view of rights claims has to take obligations seriously, since they are the counterparts to rights; it must view them as articulating the normative requirements that fall either on all or on specified obligationbearers (O’Neill 2005).

According to O'Neill, if we do not want to consider rights to goods and services as merely aspirational, then we are left with what she called "special" rights, or institutional rights. These rights cannot be considered pre-institutional, if their corresponding obligations are not pre-institutional. O'Neill's claims that institutional rights to goods and services get their obligations from human rights Declarations and 
Covenants. If this is the case, she considers that claims of their universality lack justification, and therefore cannot be considered to be human rights. "Declarations and Covenants cannot show that some particular configuration of institutional rights and obligations is universally optimal or desirable, or even justifiable" (O'Neill 2005, 432).

O'Neill's conclusion is that liberty rights are fundamental and universal, and are justifiable without reference to covenants or institutions; however, rights to goods and services are special rights that can only be justified by appeal to specific transactions, such as signing and ratifying covenants. O'Neill argues that it is not possible to assert that human rights and obligations are corollary normative claims, but that there are some universal rights without counterpart obligations. She concludes that if the identification of the corresponding obligations does not occur, then we are left with the need to reject the idea of human rights as prescriptive, instead thinking of human rights claims as aspirational (O’Neill 2005, 432).

Sreenivasan, like O'Neill, also objects to the conceptual possibility of positive rights, such as a human right to health, being considered universal. According to Sreenivasan negative rights are universal and there is no problem with identifying the corresponding obligations. However, for a positive right like health, the obligations are much more complex.

Sreenivasan sets up two main examples in order to detail what he calls his "Argument from the Nature of Health" (Sreenivasan 2012, 250). This argument attempts to show that the state, which is the only plausible candidate that could bear the duty to secure the right to health, cannot bear the correlative duty of an individual claim-right to health because the content of the right does not match the content of the obligation. 
Sreenivasan claims that the right to health demands too much; there are many social determinants involved in the right to health (i.e., food, adequate housing, clean water and sanitation, access to health care, etc.), and each of the social determinants are already covered by their own principles of justice. He attempts to argue that because they are needed for health, that more resources must be distributed to each of the social determinants of health which is too demanding, and administratively confusing. The right to health, according to Sreenivasan also demands too little from public health, stating it is beyond an individual claim-right to health. Sreenivasan uses these arguments to show that there is no correlating obligation to an individual's right to health.

Sreenivasan argues that even if the right to health does exist it is not particularly useful. What he means by usefulness concerns this notion that the human right to health and its counter-part obligations are supposed to detail concretely how this right is to be secured. If it cannot do this, then we have no use for it in the first place. Although International Declarations and Covenants describe the human right to health as a right to the "highest attainable standard" of health, Sreenivasan points out that because many countries have difficulties finding the funds for such a high standard, it should actually be thought of as a right to the "maximum of health that can be delivered under the budget constraint given by a rightful individual share" (Sreenivasan, 2012, 261). For Sreenivasan, there may not be enough resources to consider a human right to health as anything more than aspirational.

It is already difficult to determine the fair share that should be spent on the right to health in a country that has adequate funds and infrastructure in place. Sreenivasan believes this problem is exacerbated if we are looking at the issue of global health. 
Developing countries lack the requirements to distribute a fair share of resources for their citizen's health. Because health rights must either exist for everyone universally or no one, he therefore concludes that they are not plausible if so many countries are not able to secure this right. ${ }^{1}$

The main issue with the normative foundation of the human right to health that both Sreenivasan and O'Neill seem to have is that positive rights are less well founded than negative rights. It seems that for both Sreenivasan and O'Neill, positive rights are conceptually improbable because it is unclear who bears the correlative duty to secure the right. If no one has this duty, then no one can justifiably claim that they have that right. In contrast, they believe that negative rights, such as liberty rights, are perfectly plausible as the correlated duty falls on everyone. For example, if we consider the negative right to not be tortured, we can say that everyone has the duty to refrain from torturing others. To demonstrate this idea further, Sreenivasan states:

It is highly implausible to contend that 'everyone' bears the duty correlative to a moral human claim-right to health. It seems clearly false, for instance, that individual inhabitants of Mozambique... each have a moral duty to preserve the health of any given inhabitant of Brazil (let alone that of every Brazilian). The contention actually becomes preposterous if we ask, instead, whether inhabitants of Mozambique have any moral duty to preserve the health of the inhabitants of Switzerland (Sreenivasan, 2012, 144).

Sreenivasan claims that it would be impossible to say that everyone bears the duty to uphold the health rights of others. It would be implausible because the distance

\footnotetext{
${ }^{1}$ For a more detailed discussion of Sreenivasan's arguments, see section 3 of literature review.
} 
between people on opposite sides of the world would preclude any possible interaction that could be regarded as an action that would fulfill another's right to health. Because of this, we cannot say that everyone bears the corresponding duty; therefore the human right to health cannot be considered to be universal. For Sreenivasan and O'Neill, rights that are not universal are not really rights. Without an identifiable duty-bearer, there is no duty and there is no right-claim. Thus, for all of the reasons listed, Sreenivasan and O’Neill consider the right to health incoherent and implausible. ${ }^{2}$

\subsection{Concerns and Misunderstandings in the Human Right to Health Debate}

Jonathan Wolff disagrees with Sreenivasan and O'Neill and has been promoting the human right to heath: in his 2012 book, The Human Right to Health, in the 2012 article "The Demands of the Human Right to Health" and 2013's "Global Justice and Health". Wolff states that he is attempting to provide a philosophical justification for the human right to health, what seems to be absent from his work is a defense of the right to health against the major concerns expressed by Sreenivasan and O'Neill. Instead he chooses to devote a lot of time to defending it against other objections of a more practical nature that do not seem as damaging.

In his article "The Demands of the Human Right to Health ", he sets out to discuss what he claims are the five main criticisms of the human right to health. The first criticism Wolff lists is that the human right to health is too vague. Wolff claims that,

\footnotetext{
${ }^{2}$ I return to Sreenivasan and O'Neill's arguments in Section 7.2, which addresses Sreenivasan and O'Neill's arguments against the state as duty bearer for the human right to health.
} 
following Henry Shue's definition of human rights, ${ }^{3}$ we should think of the human right to health as the right to be protected from standard threats to health. There has been much debate within the literature when attempting to define the content of the right to health (Buchanan and Hessler 2002, Daniels 2008, Wolff 2012a). While this is a difficulty, it is not a criticism that threatens the existence of the human right to health.

The second criticism mentioned is much stronger. Wolff brings up O'Neill specifically, and her objection that the human right to health does not allocate duties correctly. Wolff thoroughly discusses the objection, and then sidesteps it. He admits that it is a difficult issue, and leaves it as an open-ended work-in-progress. His other articles clearly state that human rights declarations require governments to secure the human right to health for its citizens, yet he does not seem to want to directly defend his view against O'Neill's objection in this paper. Also missing from the discussion is the answer to how he can assign the duty to states in light of O'Neill's very strong points claiming the state is inadequate as the main duty-bearer. O'Neill rightly points out some of the problems with leaving governments in charge of the health rights of their citizens; 1. Governments are often the one's violating the rights of their citizens, ${ }^{4}$ and 2. There might not be enough resources available for even the most well-intentioned government to secure the right to health. Wolff again, seems to avoid providing a solution to this objection.

\footnotetext{
${ }^{3}$ For more details on Henry Shue's arguments in Basic Rights: Subsistence, Affluence, and U.S. Foreign Policy (1996), see Section 1 of Literature Review.

${ }^{4}$ This will become central to my reinterpretation of how Wolff should be building his case. I will return to it in section 7.2.
} 
The last three of the main criticisms are pragmatic concerns and do not seem particularly damaging to Wolff's view. The first objection is that the human right to health is not necessary. Wolff responds by stating that the human right to heath $i s$ necessary in that human rights empower people much more than using humanitarian aid. Wolff claims that human rights are what provides people with the chance to change the underlying structures of their nation and address the root causes of poverty. In contrast, providing humanitarian aid preserves the structure and prevents people from helping themselves in the future. In order to give people as much agency as possible, Wolff argues that human rights must be considered necessary (Wolff 2012b, 226).

The next objection Wolff addresses is that the right to health is too expensive. By using a cost-effectiveness analysis, commonly used for decision-making, under-resourced countries often have to make difficult decisions in allocating resources. However, Wolff claims that an analysis of cost-effectiveness can be a conservative economic approach to policy decisions. The example Wolff provides is the expensive task of providing antiretroviral (ARV) drugs to HIV/AIDS patients in developing countries. ARV's would provide a much healthier and productive life to those suffering and prematurely dying from HIV/AIDS; however, they are extremely expensive. A cost-effectiveness analysis would dictate that a developing country should not provide these expensive drugs for those affected by the disease. Yet, losing the productivity of so many potential workers and carrying such a heavy health burden makes the analysis seem like an example of outdated economic policy (Wolff 2012b, 233).

Although in this case it seems that the ARV's are just too expensive to afford, Wolff believes we should be asking why they are so expensive? Wolff thinks that "the 
resources should fit round the treatment programme, rather than the treatment programme fit into existing resources" (Wolff 2012b, 233). That is, we should not be so willing to accept pharmaceutical pricing that renders essential medications out of reach of those that need them (e.g. the state as duty bearer could set price controls, or make up the difference in lost revenue for pharmaceutical companies). ${ }^{5}$

And finally, Wolff addresses the complaint that vertical programmes in health policy are damaging in that they pour all resources into one health concern over all other possible diseases needing attention as well. For example, vertical programmes focused on AIDS, would take away resources and people working on malaria or tuberculosis. Wolff agrees that vertical programmes are in fact damaging, and notes that the international medical community has been moving away from the use of vertical programmes for this very reason. He also points out that vertical programmes are not unique to the human rights model, so this is not a fair objection to the human right to health (Wolff 2012b, 233).

Despite a thorough discussion of the five criticisms Wolff considers important, he never mentions Sreenivasan's main objection, which is much stronger than some of the others Wolff devotes a lot of time to in the article. Wolff and Sreenivasan clearly seem to be engaged in a debate within the literature, where the criticisms are specifically directed at Wolff; yet Wolff has made no attempt to acknowledge the main objections. ${ }^{6}$

Sreenivasan wants an answer to how a human right to health can be considered universal

\footnotetext{
${ }^{5}$ See Section 5 of Literature Review for a discussion on Pogge's innovative ideas on changing the structure of institutions governing pharmaceutical distribution in order to increase access to essential medicines.

${ }^{6}$ Sreenivasan and Wolff 's 2012 articles were part of a joint session talk on the human right to health in the recent proceedings of the Aristotelian Society.
} 
without any identifiable obligations matching the right-claims. Wolff never mentions Sreenivasan's objections, nor does he address them in his book; however his approach can provide an adequate response to Sreenivasan's concerns.

In the next section, I will show what I think Wolf's response should be to this problem. An adequate response could help solve the problem at hand, where the leading figures of the debate seem to not be addressing each other's concerns and in fact, are talking past one another. Hopefully a development of Wolff's view can not only respond to Sreenivasan and O'Neill's concerns, but also improve the strength of the normative foundation to the human right to health, currently the most important global model of health and health care.

\subsection{Wolff's Human Right to Health}

As previously mentioned, it seems that Wolff's most recent publications on the human right to health are not addressing Sreenivasan and O'Neill's major normative concerns. He raises the issue, yet does not provide a clear solution, nor does he tell us why he does not seem to be taking the objection seriously enough to provide an answer to get around this objection. Although he never states it outright, Wolff's approach can be used as a response to Sreenivasan and O'Neill, a strong response. Sreenivasan and O'Neill assume and object to a positive human right to health and what Wolff seems to be doing in his book is actually making a case for a negative human right to health.

Wolff is attempting to do quite a few different things. He wants to clarify the human right to health approach, as first introduced by Mann and Farmer. He also wants to provide a philosophically justified account of the human right to health, which is 
where his approach then separates from Mann and Farmer's. Because the human right to health, on some views of it, can look very similar to a cosmopolitan account of justice, Wolff also wants to separate a human right to health from a cosmopolitan foundation. This last goal would help Wolff defend the human right to health against the incoherence objections raised by Sreenivasan and O’Neill, as they seem better positioned to take on a cosmopolitan justification for the right to health. Wolff has not used these points in order to defend his view against the objections. This is where a development of his claims would help provide a defense of the human right to health.

Wolff's position, as I will articulate it, is particularly interesting in three ways: First, what he can be shown to offer is a negative rights approach, which makes it entirely different in normative foundation to other current cosmopolitan views that emphasize positive rights, such as theories by Farmer and Mann. Secondly, a negative human right to health avoids Sreenivasan and O'Neill's objection that it is impossible to consider a human right to health to be universal and to identify whose duty it is to fulfill this right to health. Thirdly, negative rights generally are considered coherent and justified by Sreenivasan and O’Neill, so if Wolff can make a case for a negative right to health, Sreenivasan and O’Neill might have to endorse a human right to health. However, Wolff does not seem to recognize the full value of his approach. If he did, it would be much more central in his writings and less spread out over various publications.

Wolff spends the majority of his book, The Human Right to Health (2012), discussing cases that he has pulled from Farmer's work over the years and other sources in order to demonstrate the effect that the violation of negative rights has on health. The 
AIDS pandemic generally, is used as the main example that highlights the link that Wolff, Mann and Farmer are all trying to make between health and human rights.

The evolving AIDS pandemic has shown a consistent pattern through which discrimination, marginalization, stigmatization, and more generally a lack of respect for the human rights and dignity of individuals and groups heightens their vulnerability to becoming exposed to HIV. The importance of health as a precondition for the capacity to realize and enjoy human rights and dignity must be appreciated (Mann, 1999, 12).

Farmer, in Infections and Inequalities (1999) and Pathologies of Power (2005), discussed the difference between the U.S. government's health policies during the outbreak of the HIV epidemic compared to the Cuban government's health policies. The U.S. policies were extremely discriminatory, particularly against Haitians and homosexuals who were considered to be the main source of transmission. When many Haitians were fleeing the political upheaval in their country in the early nineties, they found out that they were not welcome in the U.S. and were detained in a makeshift refugee camp in Guantanamo Bay (Farmer 1999, 52). Each refugee was tested for HIV/AIDS before being allowed them to pass in to the country and apply for political asylum. Ignoring public health laws, the Haitian refugees were forced to live in squalor for months at the Guantanamo Bay refugee camp, with no privacy and no protection from the infectious diseases to which they were susceptible. Despite warnings from other government departments about the potential impacts of an infectious disease on the camp, the camp was not closed and the sickest of inmates were not treated. Farmer quotes Yolande Jean's description of life at Guantanamo Bay for the Haitian refugees, who was interned at the base for 11 months: 
We were in a space cordoned off with barbed wire. Wherever they put you, you were meant to stay right there; there was no place to move. The latrines were brimming over. There was never any cool water to drink, to wet our lips. There was only water in a cistern, boiling in the hot sun. When you drank it, it gave you diarrhea... Rats crawled over us at night... When we saw all these things, we thought, it's not possible, it can't go on like this. We're humans, just like everyone else (Farmer 1999, 52).

It wasn't until a June 8, 1993 United States District Court ruling declared the camp unconstitutional, that a few of the imprisoned refugees were allowed to enter the United States (Annas 1993, 591). The legal battle was waged by a grassroots campaign that advocated for these men, women, and children by bringing their cause before U.S. courts. This severe discrimination against the HIV infected individuals in the U.S. was, at a policy level, meant to prevent HIV/AIDS from spreading across the U.S. However, the U.S. did not manage to contain the spread, and their policies turned out to be quite ineffective.

In contrast, Farmer argues that Cuba handled the beginnings of the HIV/AIDS crisis quite differently. HIV-positive Cubans were also initially quarantined; however, in contrast to Guantanamo Bay, Santiago de las Vegas, an old hacienda outside of Havana was not run like a prison camp nor were the ill patients living there treated like criminals. According to Farmer, when visiting Santiago de las Vegas, the residential units looked more like middle class housing in Cuba. Each of the units where patients and their families lived included the comforts of air conditioning and televisions (Farmer 2005, 70). Patients at the hacienda were given round-the-clock medical care by disease specialists and nutritious food, and were released when they were able to demonstrate they understood how to live responsibly with their disease and not spread it to others. 
With these measures taken, Cuba was able to contain the spread of AIDS throughout their country and was the least affected country in the Western hemisphere (Farmer 2005, 72).

This example demonstrates the difference between two countries, both attempting to contain the spread of an infectious disease. One country violates the human rights of those already infected, and one does not, resulting in very large differences in the spread of the disease, therefore showing that the respect for human rights can have a large impact on public health. The contrast between the government actions of the U.S. and Cuba helps show what Wolff has in mind when he argues that violating the human rights of those suffering of HIV/AIDS violates their right to health. Had the U.S. government not discriminated against the Haitian refugees, the refugees would not have had their right to proper medical care violated at Guantanamo Bay. Had the U.S. not discriminated against Haitians already in the U.S., and gay communities, the spread of HIV could have been better contained.

Particularly relevant to the prevention of AIDS was the protection of an individual's right to information and access to crucial anti-retroviral medications and treatment. In the first case, the importance of the right to information can be seen if we compare the public health policies in regards to AIDS in Uganda and South Africa. Uganda right at the outset of the AIDS outbreak launched a public information campaign, providing accurate information to the public explaining how the disease was spread and how to protect themselves (Wolff 2012a. 72). As a result, Uganda was able to keep its rate of infection around 7 percent, which is quite low compared to its neighboring countries (Wolff 2012a. 72). In contrast, South Africa tragically promoted information about the transmittal of HIV/AIDS that was not correct. This resulted in staggeringly 
high rates of infection within the African nation (Wolff 2012a. 74). President Mbeki was a proponent of "African solutions for African problems", which in the case of HIV/AIDS, meant he blocked access to Western anti-retroviral treatments.

Notoriously, as recently as 2003 Mbeki's then health minister, TshabalalaMsimang, urged South Africans to eat beetroot, garlic, lemon, olive oil, and African potatoes to boost their immune systems rather than take antiretroviral therapies. This caused outrage and ridicule on the world stage, and dismay and embarrassment in South Africa where she became known as 'Dr. Beetroot,' and was trenchantly criticized by civil society groups for violating the human right to health of those who needed treatment (Wolff 2012a, 73).

The confusion over HIV/AIDS in South Africa continued, leading to false rumors of alleged cures. The most alarming was the belief that having sex with a virgin could cure AIDS. This resulted in widespread rapes of young girls and disabled women who were assumed to be virgins as well, spreading the disease even more (Wolff 2012a, 73)

Both countries, Uganda and South Africa, show the close connection between human rights and health. The cases also raise the issue of the right to access of medical treatments. As previously mentioned, both Mann and Farmer have emphasized the fact that AIDS has become a disease of the most vulnerable in society. With the pandemic raging in some of the poorest nations in the world, how those affected can afford the expensive anti-retroviral treatments to keep them alive has become a prominent issue in the human right to health issue.

Given that Wolff, like Farmer and Mann, spend so much time on these examples, comparing countries that violate their citizen's human rights to countries that protect their 
rights, we have to consider what it is that they are trying to tell us. Wolff does something Farmer and Mann do not, which gives us some insight. He says there are three categories of government obligations, "the duty to respect, the duty to protect, and the duty to fulfill"” (Wolff 2012a, 29). It is from examining his discussion of these three duties, coupled with his discussion of the previous examples, that we can truly see what is unique about his approach and that it generates a new type of normative view that can withstand Sreenivasan and O'Neill's objection.

Typically the right to health is viewed as a positive social and economic right. It is thought of as a claim that people can demand for the fulfillment of all, or some determined amount of social services that affect the social determinants of health. This perception of health rights as only a positive right seems to be the fault of the original drafters attempting to formulate the right to health in article 12 of the ICESCR. The Covenant stressed the importance of creating and improving upon institutions and infrastructure that improves access to medical services and a clean environment. This definition has continued to shape the way we define the content of the human right to health.

While the points mentioned in the ICESCR are all important factors of a positive right to health, there was no mention on how human rights violations and discrimination seriously impact health. Farmer and Mann both discussed the positive right to health with

${ }^{7}$ The distinction between the duty to respect, protect and fulfill comes from the Maastricht Guidelines on Violations of Social and Economic Rights (1997, Section 2.6 The meaning of violations of economic, social and cultural rights: Obligations to respect, protect and fulfil). "Like civil and political rights, economic, social and cultural rights impose three different types of obligations on States: the obligations to respect, protect and fulfil. Failure to perform any one of these three obligations constitutes a violation of such rights". 
their approaches. They were also the first to point out some unique features of the right to health that differentiated it from other social and economic rights. What makes health rights particularly distinctive are that they are inextricably linked to negative human rights.

The duty to respect citizens' right to health particularly involves nondiscriminatory actions, such as ensuring that certain minority groups are not excluded from receiving health care services, impeding the distribution of certain necessary medications, not allowing unsafe drugs to be sold to the population. Governments should also,

...not force coercive treatments upon people except in some cases of mental illness or communicable diseases. They should refrain from limits on contraception and they should not withhold health-related information. They should not pollute the environment or test nuclear weapons if this leads to unsafe release. And they must not limit health service access as a punitive measure (Wolff 2012a, 29).

Although not an exhaustive list, this shows many government duties that fall within the category of not violating the rights of their citizens. We should understand a government's duty to respect citizens' rights as a negative duty to refrain from certain actions or policies that would infringe on their citizens' right, harming them in the process.

Wolff's next category of government duty is the duty to protect. Governments have a duty to protect a citizen's right to health from being interfered with by others. According to Wolff, examples of the duty to protect could include: 
Ensuring that private health provision does not undermine equitable access for all, and the licensing and regulation of medical professionals. It also includes protection from 'harmful social or traditional practices' (Wolff 2012a, 30).

The inclusion of protection from harmful social or traditional practices can be considered quite controversial. Many debates have been waged over practices that some view as traditional to certain cultures, and others think of as harmful or oppressive, such as genital mutilation, for example. Setting the issue of cultural differences aside, the duty to protect is meant to ensure that any rights granted to individuals by their governments are not infringed on by others in society.

The last category of government duty Wolff discusses is the duty to fulfill. It is this duty that involves elements of a positive right to health such as providing health services, ensuring a national health policy, and providing humanitarian or disaster relief when required. Wolff includes this in his listing of government obligations, however the focus of his book is primarily on the duties to respect and protect. Wolff mentions that we can use aspects of Farmer's cost-efficient model to try and provide more health and health-related services (Wolff 2012a, 139). Additionally, we can certainly also maintain Farmer's intentions, that the right to health is never something that should be given up on, and that there are creative ways to get around problems that seem insurmountable at first.

Wolff takes the right to health as a negative right, although he never explicitly says this. Instead he gives us chapters of examples and cases, and focuses on the duty of governments to respect and protect the right to health, particularly demonstrating how discriminatory government policies have a direct effect on the health rights of citizens. It 
seems that the duty to respect and protect are the obligations that Wolff thinks governments can take on right away, and aspire to the duty to fulfill.

Wolff claims that his view follows the Declarations and Covenants currently set out by international human rights law as normative guidelines. The fact that the Declarations and Covenants involve both negative and positive duties is part of the confusion in Wolff's approach. At times, he seems to slip back and forth between the discussion of health as positive right and health as a negative right. However, the bulk of his discussions of the right is demonstrating how discrimination and the violation of rights negatively impacts health.

The International Covenant on Economic, Social and Cultural Rights states that everyone should enjoy "the highest attainable standard of physical and mental health" (ICESCR, Article 12.1). It is thought that in order for this to be accomplished, the right to health would have to be thought of as a positive right to health. There would be a need to address all of the social determinants of health, and secure them at quite a demandingly high level. Everyone globally would need clean environments, access to the highest standard of medical services, access to education, adequate housing, proper nutritious food, etc. However Article 12 of General Comment 14 states the right to health in negative terms. Article 12 highlights actions that do not require many resources and can be taken on by poorer governments right away. Some of these less expensive, but extremely important actions are outlined in the following list quoted from section 12 of General Comment 14:

12.(b) Accessibility. Health facilities, goods and services have to be accessible to everyone without discrimination, within the jurisdiction of the State party. 
(i) Non-discrimination

(ii) Physical accessibility

(iii) Economic accessibility (affordability)

(iiii) Information accessibility (UNHCHR General Comment 14, 2000)

One purpose of General Comment 14 is to provide a clear statement to the international community that governments allowing for discrimination against certain groups, such as discrimination against people with HIV/AIDS, are in violation of such groups' right to health. The human right to health has gained support from the international community over the years due to an increased awareness of the enormous inequities between affluent countries and developing countries. Particularly when it comes to health concerns, there is a severe injustice existing in the world, where some have access to the best medical treatments, the best nutrition, clean water, and all other social determinants of health, while others have nothing at all.

Part of the confusion in understanding Wolff's claims could stem from the fact that he is using the Declarations and Covenants as guidelines, which include positive and negative duties. However, it is interesting that he points out that they do include a negative right to health, as well as the positive conception. This is not commonly discussed in the human right to health literature.

According to Wolff a human right is a claim against one's government, whose duty it is to respect this right according to binding international law. If the government fails to do so, a second-order duty falls on the international community to help secure the government's duty (Wolff 2013, 88). According to this view, Wolff claims that this would change the international community's duties from a focus on aid to a focus on enforcement. " $\ldots$ conceiving of health as a human right changes the duties of the 
international community essentially from aid worker to policeman, with diplomats and lawyers, rather than doctors and nurses, the active agents" (Wolff 2013, 88). This change also shows a shift from thinking of the right to health as a positive duty for assistance to a negative duty that enforces rights violations in order to protect people from harm.

\subsection{Identifying a Duty Bearer: Developing Wolff's Claims as a Possible Response to Sreenivasan and O'Neill}

My interpretation of Wolff and the reason for his extensive discussions of cases of political and civil rights violations helps us make sense of what Farmer and Mann were pointing out and how this helps us normatively ground the human right to health approach. The cases demonstrate the negative impact on the physical, mental and social well-being of all individuals affected. The relationship between human rights and health is clear when considering the obvious examples of human rights abuses such as torture and inhumane or false imprisonments. Health impacts, however, can go beyond these instances. Mann has pointed out that the duration and extent of the impacts on the health of those whose rights are violated are often severely underappreciated. Victims of human rights abuses often suffer lifelong effects on their mental and social well-being beyond just their physical well-being (Mann 1999, 15).

Wolff's case studies cover violations of rights that can have dramatic health consequences that we would not necessarily think of as being related to health, such as a violation of the right to information. Countries such as South Africa have adopted policies of abstinence rather than providing easy access to condoms, or providing 
inaccurate information about how to avoid contracting HIV/AIDS. This denial of medical facts violates an individual's right to know how to protect themselves with the best most up-to-date medical information. An abstinence policy also prevents citizens from accessing what they need to keep themselves safe (i.e. condoms). This violation of their rights, consequently, had a severe impact on their health, and most certainly led to the spread of the disease. With the examples used, we can see that it is not just violations of social and economic rights that can impact an individual's health, but also infringements on their political and civic rights (Wolff 2012a, 73).

In contrast to South Africa's policies of denying medical facts about the transmission and treatment of HIV/AIDS, Uganda approached the epidemic differently. Right at the onset of the spread of HIV, Uganda developed a strong and quick campaign to educate its citizens on this new disease. Information was given on how it spreads, how to protect oneself, and later on, which medical treatments were helpful. This educational campaign prevented Uganda from being hit with the disease as heavily as its neighboring countries (Wolff 2012a, 72-74).

Considering the duty to respect and protect are obligations drawn from negative rights, they should be considered universal according to the standards discussed in Sreenivasan and O'Neill's papers. We can use Wolff's position as a direct response to their objections. The main issue Sreenivasan and O'Neill have with the right to health is that there is not a plausible candidate to secure the corresponding obligations to the right to health. However, Wolff does identify who holds the associated duties to respect and protect the right to health. He considers governments to be a plausible candidate for these types of duties. Both governments in developed and developing countries can 
maintain these obligations without cost being an issue, as these are very often simply changes in policy that are needed (Wolff 2013, 88).

Wolff also identifies second-order obligations to be taken on by the international community if, in case, governments are unable or unwilling to respect and protect the right to health. Sreenivasan and O'Neill have several objections to governments being responsible for securing the right to health that Wolff has not addressed. Section 7.2 will take a closer look at each of them and how, I believe, that Wolff's approach can account for these objections. First, the next section will differentiate Wolff's claims from a cosmopolitan-based conception of the human right to health.

\subsection{Cosmopolitanism and Wolff's Health as a Human Right Position}

In order to further clarify Wolff's position and how he distinguishes his view from a cosmopolitan-based view, we should specifically differentiate it from Pogge, as his view is a leading cosmopolitan approach to health and human rights. Pogge conceives of a cosmopolitan global justice scheme that focuses on the well-being of individuals as citizens of a global world and envisions an egalitarian global society that redistributes the benefits and burdens between nations in order to establish background fairness on a global level. (Pogge 2008)

Turning to the normative foundation of Pogge's theory of global justice, he argues that we have a strong negative duty to reduce the harms imposed on the poor by the global order. As the affluent benefit from the unjust economic system that is harmful to the poor, we owe them compensation and therefore have a moral duty to assist. 
For Pogge, global justice is about offsetting an unjust institutional redistribution from the poor to the rich. His strategy for redistributing the global wealth is the Global Resource Dividend, a global tax on the consumption of resources. The tax is based on the premise that all persons in the world have an entitlement to a share in the profits produced by the use and sale of natural resources. The natural resources of the world are supposed to be here for the common good, and it is a morally arbitrary point that some people are born in resource rich countries, and some are not. Even within the same country, it should not be morally important that some people have the opportunity to profit enormously on the resources available within the geographical territory, while others do not. The Global Resource Dividend then, is put in place in order to tax wealthy consumers of resources (Pogge 2008, 214).

In terms of health rights, Pogge uses what he calls the Health Impact Fund (HIF) to ensure access to vital medications globally. He focuses on the role of pharmaceutical companies and the World Trade Organization's TRIPS Agreement (The Agreement on Trade-Related Aspects of Intellectual Property Rights). TRIPS aids pharmaceutical companies in recouping their research and development costs when developing new medicines by ensuring a 20 year product patent, thereby blocking competition from other medical manufacturers from producing cheaper generic versions. This system ensures that all profits go to the pharmaceutical company that originally developed the new drug (Pogge 2012, 7).

The way this system is currently set up maintains high prices of essential drugs that are too expensive for the developing world to afford. Pogge's HIF removes the 20year patent, instead giving pharmaceutical companies the option to register new drugs, 
allowing them to be made available at the lowest possible cost. The incentive would be that in exchange for making the drug available, the pharmaceutical company would receive a payment based on the drug's global health impact over the first ten years. Therefore, essential medications would be accessible to those who previously could not afford them, and the pharmaceutical companies would still be able to recoup their research and development costs, ensuring the incentive for the creation of new and innovative drugs is maintained (Pogge 2012, 7).

Although Pogge's approach is similar to Wolff's in that they are based on the violations of negative rights, Pogge's cosmopolitan foundation differentiates the two views. A cosmopolitan approach assigns duties to everyone, however these duties are indirect. Everyone should fulfill their obligation to not harm the poor, however not everyone has the ability to specifically change the unfair global order. Instead, Pogge's focus is on the direct positive duties of the international community to change the global institutions that are unjust, such as changing trade policies and ensuring a more just distribution of wealth and essential medicines by using a Global Resource Dividend and the Health Impact Fund.

Wolff's focus is on the duty that governments have to not violate their citizen's rights and how that specifically impacts their health. In Wolff's opinion, the question of who bears the duty of human rights claims is what separates cosmopolitanism from the his negative human rights approach. On a cosmopolitan account, the duty falls on everyone. Wolff identifies the duty bearer as the government. Second-order duties fall on the international community, as well as citizens within the country. It is their duty to attempt to enforce and pressure the government to secure the rights. This might even at 
times mean forcing a change of government that is able to follow through on their duties. As a last resort, this approach identifies a more general duty on all citizens of the world to help the citizens of the country secure their rights. Wolff is clear that this last duty, which is the same as a cosmopolitan account of duty, is only a last resort if all else fails (Wolff 2013, 88).

Wolff's view focuses on governments that fail to respect and protect the human rights of their citizens. It is not a positive attempt to fulfill a human right to health. To clarify the difference, we can compare a positive right to health to what a negative right to health might look like. A discussion of a positive right to health typically involves a debate about the content of this right. It is generally thought to contain claims to some or all of the social determinants of health, i.e., access to clean water, health care services, sanitation, adequate working conditions, decent housing, and nutrition.

This is not quite the same as what Wolff is advocating. A negative right to health is not really a discussion of the content of the social determinants of health. It is focused on the relationship between individuals' health and their human rights being respected and protected by their government. Violating liberties negatively impacts health, and therefore is also violating the citizen's right to health.

Wolff claims that this view is less demanding than a cosmopolitan foundation for the human right to health. A cosmopolitan account would demand the same standard of health services in the developed world also be provided in the developing world. As the developed world at this time has access to a level of health care that is many times higher than what would be required in order to say a developed country has met the lowest minimum health standards required, a cosmopolitan account insisting that these two 
extremes are on a more equal level is very demanding. Wolff's approach does not justify the content of the human right to health based on a common standard across all countries; instead it is based on a government not violating the human rights of its citizens.

The emphasis on the obligations to respect and protect make up the negative right to health that is unique to my interpretation of Wolff's position. Sreenivasan and O'Neill's objection to a right to health does not apply to the two categories of obligations that Wolff focuses on in his approach. By pointing out how much can be accomplished by simply focusing on the duties to respect and protect, much can be done to promote the human right to health without even going into elements of a positive right to health.

\subsection{The Plausibility of the State as Duty-Bearer}

When attempting to answer the question of who bears the duty to secure the right to health, a common answer is that it is the state's duty to secure the right for their citizens. Wolff is one advocate of this view, which Sreenivasan calls the "state-by-state view" (Sreenivasan 2012, 245). Wolff claims the moral duty to preserve the health of individuals is borne by the state. Sreenivasan has two objections to this:

1. The state-by-state approach does not cover the universality needed as there are too many people globally that fall under the stateless category and therefore would not have a government whose duty it is to secure their right to health.

2. Whether the state of Mozambique is fulfilling its moral duty to preserve the health of its citizens depends, inter alia, on what the applicable standard of health preservation is. The universality of moral substance - one world, one standard-is arguably as fundamental to the idea of human rights as the universality of right- 
holding. Very poor states are not plausible candidates to bear the moral duties correlative to human claim-rights to health and 'everyone' is not a plausible candidate either (Sreenivasan 2012, 245).

Sreenivasan concludes that, therefore, it remains obscure whether anyone has a moral duty to preserve their health (Sreenivasan 2012, 245). However, we need to assess whether or not Sreenivasan's objections would hold against Wolff's view if it is not the positive right to health that Sreenivasan assumes. Sreenivasan's first objection, that many people are state-less and therefore do not have a government to which they can claim their right to health entitlement, does not seem to work as an objection against Wolff's view. Often stateless people are refugees and new immigrants, both legal and illegal. These are groups that are specifically discussed in Wolff's work. It is true that people fleeing their home country and landing on foreign grounds do not technically have a government. However, it is up to the country that they are seeking asylum with to respect and protect their human rights. International immigration law covers various forms of discrimination specifically so that a government cannot violate the rights of refugees. While a government might not fulfill refugee claims for a positive right to health, they do have the duty to respect and protect refugee human rights regardless of the fact that the refugees are not citizens of their country.

Sreenivasan's second objection seems like it would be better directed a cosmopolitan foundation for the human right to health (Sreenivasan 2012, 245). As we previously discussed, Wolff's position does not have the same health standard demands as a cosmopolitan approach. A cosmopolitan foundation is always based on the notion that all people in the world, regardless of their citizenship, should be considered to have the same moral worth. In regards to health rights, this means that the right to health is to 
be held by a common standard. Citizens of developing countries ought to have access to the same standard of care as those in the developed world. This is not necessarily the case for Wolff's approach. His less demanding view dictates only that the human rights of all citizens of the world are not violated. Governments that are poor can still be considered to be plausible candidates to bear the corresponding obligations to this negative right to health.

O'Neill also has an issue with state's bearing the duty to secure health rights. She believes that states are usually given this role because it is only states that have the power that makes it possible to secure the second-order obligations to allocate the first-order obligations and their corresponding rights to individuals and institutions. She claims that it is the state that generally is the one that holds the power. However O'Neill does not think that the state ought to be assigned this duty. She argues that they are not the best ones for this role. Many states violate the human rights of their citizens, which as O'Neill says, "may be rather like putting foxes in charge of the hen houses" (O'Neill, 2005, 435). Other states follow self-interested policies, rather than pursuing the rights of their citizens. In addition, there are some states that do wish to secure the human rights of their citizens but lack adequate resources to do so. O'Neill concludes that it might be better to leave some of the second-order obligations to non-state actors, such as NGO's, transnational corporations, or religious, cultural and educational bodies (O'Neill 2005, 435).

O'Neill's observation that many states violate the rights of their citizens is certainly an important objection. Many states do no not uphold the international law standard, and not just poor corrupt countries, but also developed countries that have 
ratified the UN international Declarations and Covenants. However, this observation does not mean that a negative right to health does not exist. Wolff's approach includes international support for situations where governments have failed to respect and protect the rights of its citizens. Furthermore, Wolff's take on the right to health would not be damaged by thinking of it in terms of the progressive realization of the right to health. It is a fact that in our current political climate, many states violate the human rights of their citizens, but most would agree this is something that should change.

The deepest problem with establishing a human right to health for O'Neill is that the obligations assigned to states by international Declarations and Covenants are not the corollaries of the human rights listed. O'Neill makes the argument that the International Declarations and Covenants that assert universal human rights only assign states secondorder obligations to secure them. The Declarations and Covenants do not assign firstorder obligations to respect liberty rights because they are to be respected by all, not just states (O’Neill 2005, 433). However, they do assign states second-order rights to secure respect for liberty rights. They also do not assign first-order rights to states to secure rights to goods and services, but they do assign second-order obligations in order to secure the rights. If the obligations are only second-order, then they cannot possibly correlate to the first-order universal human rights that are proclaimed in the Declarations and Covenants.

States party to a Covenant are seen as acquiring special obligations by signing and ratifying the instrument. It would then be clear that those special, second-order obligations did not have counterpart rights, let alone counterpart universal human rights. They are second-order obligations. This could be helpful, as obligations without counterpart rights are 
normatively coherent (unlike rights without counterpart obligations), we can take a normative view of the obligations assumed by states that sign and ratify the Covenants, and can see them as setting requirements (O'Neill 2005, 433).

O'Neill claims that if the second-order obligations that are assigned to states cannot be seen as the counterparts to the universal human rights being recognized in the Declarations and Covenants, then these obligations also do not define the first-order obligations that would be the counterparts of the human rights. So contrary to Wolff's argument, that we can determine the obligations of states by using the Declarations and Covenants as a normative guide (Wolff 2012b, 219), O’Neill claims that these secondorder obligations do not inform the first-order obligations that would be the appropriate counter-part to the human rights proclaimed in the Declarations and Covenants. The human rights must have a matching set of obligations for the rights to have any normative force. If not, the rights can only be considered to be aspirational.

Wolff seems to be using the Declarations and Covenants differently than O'Neill's objection suggests. Rather than being the source of the corresponding obligations, the declarations provide the enforcement that Wolff wants. Wolff claims that the international Declarations and Covenants can be a normative guide; however they aren't simply institutional rights as O’Neill suggests. If Wolff is promoting a negative human right to health, then it should be considered universal and pre-institutional in the same sense that O'Neill claims that liberty rights are considered universal human rights.

The incoherence claims that Sreenivasan and O’Neill issue against Wolff only hold if he is promoting a positive right to health. A negative human right to health would consist of a claim for one's rights to not be violated by one's government. The 
corresponding duty to this right does not come from the declarations and covenants. Instead, it would be a universal duty for all people to not infringe on this right, but enforced by governments and laws in the same way liberty rights are respected and enforced.

\subsection{Conclusion}

Wolff's approach does not make any significant suggestions for fulfilling a positive duty of assistance. The emphasis is solely on respecting and protecting human rights and the impact this has on health. This can be seen through the many cases and scenarios he spends chapters discussing. The cases show that the policies governments use can directly impact the health of their citizens. When the U.S. used discriminatory policies against those with HIV/AIDS, the affected were unable to get the treatment that they needed and needlessly suffered. The HIV virus was also not contained well, resulting in a spread throughout the U.S. Cuba's non-discriminatory approach provided much better treatment to those that were infected with HIV, as well as managing to contain the spread of the disease better than any other country (Farmer 2005, 70). South Africa's policy of denial that was used instead of Uganda's policy of education also dramatically showcases the difference between the respect or violation of rights and the impact it has on health (Wolff 2012a, 74).

My interpretation of Wolff's approach suggests that he uses examples from Farmer and Mann's work, and the history of the HIV/AIDS pandemic to demonstrate the severity of health impacts when governments violate the rights of their citizens. Rights such as freedom of speech, the right to information and privacy, seemingly unrelated rights to health are, in fact, inextricably linked to health. When these rights are violated, 
health is negatively affected. It shows that it is not always just an issue of access to health care or other positive duties that have been the main focus of the discussions on the right to health. Missing from these discussions was a whole other section of rights that when respected and protected can further people's right to health.

This approach to the human right to health can show that it is a mistake to dismiss the health as a human right model on the basis of it being too expensive, not universally attainable and incoherent. A focus on the negative right to health highlights all of the immediate and inexpensive work that be done to promote the right to health around the world. Furthermore, the use of the United Nations Declarations and Covenants can provide an outline for the immediate work that can be accomplished in improving health rights as well as a tool for enforcement.

My development of Wolff's view can provide a defense against the many damaging objections that philosophers like Sreenivasan and O'Neill advance against the human right to health approach. The question of who bears the duty to secure the right to health is clear when looking at it as a negative duty. Governments, following international declarations and covenants bear the duty for their citizens. All human beings may demand these rights, including those considered stateless. Pre-institutional negative rights coherently have pre-institutional corresponding duties. Therefore, by further substantiating Wolff's position, it can be considered a coherent way of defending the human right to health approach.

I began this paper by discussing the difficulty in being able to articulate a concept as complex as the human right to health. Despite this, we can establish a moral foundation for the human right to health approach that can help defend it against the 
heavy skepticism of its existence. The acceptance and eventual fulfillment of the human right to health can hopefully one day thwart some of the suffering and preventable deaths that are unfortunately a part of everyday life for millions of people. 


\section{Chapter: Literature Review}

The human right to health draws on literature from many diverse areas of thought. It relies heavily on human rights theory, and combines literature from various areas of political philosophy, bioethics, and discussions of international development. This section will provide a more thorough review of the relevant background literature that informs the human right to health approach. The central question this literature review aims to address stems from the human right to health debate currently dominating the literature. This question is whether or not we can provide a normative foundation for the human right to health. The central figures in this debate are Jonathan Wolff, Gopal Sreenivasan, and Onora O'Neill. I will focus on a discussion of the relevant literature that demonstrates the development of the fundamental ideas (both theoretical and practical) of the human right to health and where there are gaps in the current literature. This literature review will include the following sections: human rights, proponents of the human right to health approach, critics of the human right to health approach, theories of global health, and lastly, theories of global justice.

\subsection{Human Rights Literature}

A detailed discussion of the human right to health requires some background literature in human rights theory. In particular, the work of Henry Shue (1996) and Charles Beitz (2009) has provided much to the current debate on the human right to health. Some of Shue and Beitz's main concepts and arguments about human rights and their corresponding duties have been used in Jonathan Wolff's (2012) arguments for the human right to health, as well as in Sreenivasan (2012) and O'Neill's (2008) objections. 
This section also includes an overview of the United Nations Human Rights Declarations and Covenants that serve as guidelines for human rights law.

\subsubsection{Shue's Basic Rights}

Shue's extremely influential book, Basic Rights: Subsistence, Affluence, and U.S. Foreign Policy (1996), serves as a starting point for most of the other literature reviewed in this section. Many of the human rights concepts in current literature originated from Shue's work. Shue promotes the central thesis that everyone has basic rights to security and subsistence. Rights to security would cover protection from any standard threats or violence. Subsistence rights similarly cover needs that are seen to be crucial to one's basic survival, such as adequate food, housing, and health care. Shue defines basic rights as a right whose "enjoyment is essential to the enjoyment of all other rights" (Shue, 1996, 19).

Take any right you believe yourself to have. Call this right R. Now consider the background conditions that would have to be satisfied in order for you to enjoy R. You will find on reflection that these conditions include guarantees of security and subsistence. Without these guarantees, you could not enjoy R (Shue 1996, 29)

That is, if one is suffering from malnutrition or is physically harmed, for example, that person would be prevented from enjoying other rights such as voting. Both the rights to security and subsistence are considered to be equally basic. A right to security correlates with negative duties of non-interference and the right to subsistence correlates with positive rights. Neither is considered more important than the other, and neither is considered to be of more value than other non-basic rights. 
Before Shue's book was published, negative and positive rights were commonly distinguished and separated (see Cranston 1973). It was thought that negative rights were clear in the identification of duty-bearers, and were not expensive and complicated like positive rights. Negative rights were thought to have correlated to negative duties, and positive rights correlated with positive duties. The positive duties were the only duties that were too expensive to be considered attainable for everyone.

Shue argued that this distinction was mistaken. He claimed that negative and positive rights each produce a combination of negative and positive duties; therefore both negative rights and positive rights can be equally expensive to secure. (Shue 1996, 38) The only useful distinction between negative and positive rights according to Shue is in their duties. Some rights will involve duties where we refrain from certain actions or causing certain harms, and other rights involve duties where an action must be performed or certain commodities given in order to fulfill the right. Often, it may be a combination of the two kinds of duties (Shue 1996, 52).

Shue then suggests that there are actually three types of duties that correspond to every basic right, positive and negative:
I. Duties to avoid depriving
II. Duties to protect from deprivation
III. Duties to aid the deprived (Shue 1996, 52)

Shue's distinction between the three types of duties is still used in current health rights literature. It is often described as the duties to respect, protect, and fulfill human rights. Human rights, according to Shue, are to protect individuals from what he calls "standard threats". Standard threats would consist of threats to physical security and 
threats to economic security and subsistence.

A right involves a rationally justified demand for social guarantees against standard threats [which] means, in effect, that the relevant other people have a duty to create, if they do not exist, or, if they do, to preserve effective institutions for the enjoyment of what people have rights to enjoy (Shue 1996, 17).

The right to health is considered a necessary subsistence right required for the enjoyment of all other rights. Shue's work has also influenced the very established argument for health rights, which is the right to a decent minimum of health advocated for most prominently by Allen Buchanan (Buchanan 2009).

\subsubsection{Shue's Institutional Approach to Human Rights and their Corresponding Duties}

When it comes to identifying who holds the responsibility for securing health rights, we can turn to another one of Shue's very influential papers, "Mediating Duties" (1988). In this article Shue claims that in a globalized world, everyone's actions affect others, as we are all part of an international economic system. The only feasible way that our obligations to distant strangers can be fulfilled is through the use of institutions. (Shue 1988, 694) This means that everyone has an indirect moral obligation to support institutions, which in turn have a direct obligation to help those in need. In terms of helping people in the developing world, citizens of the developed world have a duty to aid institutions that directly help support the development of nations. Shue's very reasonable point is that it is not feasible for people to support everyone and all institutions in every way possible. This is too morally demanding and inefficient. His 
solution is a moral division of labour that attempts to establish how the corresponding duties would be assigned.

Universal rights, then, entail not universal duties but full coverage. Full coverage can be provided by a division of labor among duty-bearers. All the negative duties fall upon everyone, but the positive duties need to be divided up and assigned among bearers in some reasonable way. Further, a reasonable assignment of duties will have to take into account that the duties of any one individual must be limited, ultimately because her total resources are limited and, before that limit is reached, because she has her own rights... One cannot have substantial positive duties toward everyone, even if everyone has basic rights. (Shue 1988, 690)

Shue makes the claim for using institutions based on two advantages that this approach would bring. The first is efficiency. (Shue 1988, 696) He argues that institutions obviously have the ability to help those in need far more effectively than any single individual, or multiple, uncoordinated individuals. "The purpose in assigning duties, after all, is not for duty-bearers to suffer more but for right-bearers to enjoy more of what they are entitled to." (Shue 1988, 697) If the ultimate goal is help those in need secure basic rights, we would then want the most efficient and quickest way for this to occur. For Shue, this means that in the assignment of duties, the key element is that whoever has the greatest ability to efficiently secure the rights of another in need is the person that should be assigned the corresponding duty.

The other principle that Shue mentions in his article is that institutions provide respite - a psychological buffer — from being faced with all of the suffering in the world. "It is not necessary or desirable for each conscientious individual constantly to confront the hollow-eyed stare of every hungry child in the world... If mediating institutions have 
a sheltering psychological effect, that is good." (Shue 1988, 697) To illustrate this, he gives an example of nurses that take care of suffering patients all day. Is it reasonable to then assign to them a direct moral duty that involves dealing with more suffering? This would likely be too much for any person to psychologically handle, resulting in poor performance when on the job. Being a nurse is an important role in society, and alleviates the suffering of many, and we should not take away from their role as nurse by adding on the extra moral duty of directly alleviating the suffering of more people.

Many when attempting to provide a solution to the assignment of duties have used Shue's idea of a moral division of labour. Particularly relevant to this discussion, it has been used by Wolff and Buchanan in each of their own conceptions of health rights, or used in their human rights models more generally, like Charles Beitz.

\subsubsection{Beitz's Two-Level Model of Human Rights}

Charles Beitz's The Idea of Human Rights (2009) is another very influential work in human rights literature, and is also heavily influenced by Shue's Basic Rights. Beitz's "practical conception of human rights " uses human rights doctrine and the everyday practice of international politics as the guide for a human rights conception (Beitz 2009, 102). A practical conception allows for people to disagree about the reasons grounding human rights discourse while still allowing them to agree on human rights practices. (Beitz 2009, 104)

Beitz proposes a two-level model of human rights. Following Shue (1996), this model consists of a normative division of labour between the responsibilities of states and the international community and the responsibilities they each bear. States are the 
primary duty-bearers for ensuring that the human rights of the citizens are respected and protected (Beitz 2009, 109). The international community would have a second-level obligation to guarantee that the states fulfill their responsibilities and secure the human rights of the citizens (Beitz 2009, 108). The Model has 3 Elements: (Beitz 2009, 109)

1. Human rights are required in order to protect 'urgent individual interests' standard threats that they may typically encounter as citizen of a state.

2. Human rights apply to political institutions of states. This includes constitutions, laws, and national public policies.

3. Human rights are an international concern. The international community may need to act if governments fail to fulfill their responsibilities (Beitz 2009, 109).

The governments of a state are considered to have violated human rights when they fail these requirements. This remains true even if a government did not intend to violate a human right. As Beitz claims:

A government might be said to have violated a human right even when there is no intention to do so (e.g. through a lack of capacity or poor policy planning) and when the proximate cause of the deprivation is something other than government action (e.g. when a government fails to take the appropriate preventative or remedial steps) (Beitz 2009, 109).

Beitz addresses Onora O'Neill's main concern about human rights; rights cannot be considered universal without corresponding universal obligations. Beitz states, "In her view, this stricture is violated by any conception in which the obligations to respect someone's ("universal") human rights are held only by members of that person's own society or by its government" (Beitz 2009, 119). Beitz believes his two-level model of 
human rights addresses O'Neill's issue with governments being in charge of the obligations to fulfill the rights for their citizens. Beitz's model assigns the primary responsibility to states; however, the second-level obligations of the international community are meant to ensure that states do not violate the rights of their own citizens, intentionally or not.

Beitz also addresses another important concern; critics of human rights models claim that human rights are supposed to provide enough information in their content to inform us of who is claiming what and to whom. Beitz disagrees that human rights are supposed to provide all of this information. He states,

Within the practice of human rights, a valid claim of right is less information-rich. It conveys information about the nature and importance of the benefit or harm, the likelihood that eligible agents will have reasons to act, and the aims at which their action should be directed, but in the general case it tells us less about the identity of the agents whose conduct is regulated and the circumstances in which it would be permissible not to comply (Beitz 2009, 119).

Beitz disagrees with the common criticism that human rights are supposed to provide information about who has the responsibility to secure the right. It serves its purpose as an indicator of a need that should be addressed or a harm that is occurring and directs the arrangements required to resolve the issues. However it does not specify the exact details, nor does it need to in order to be useful. However this is why human rights are often called "manifesto rights" rather than "real" universal rights. "Manifesto Rights are not necessarily correlated with the duties of any assignable persons because under 
widely prevalent conditions of scarcity and conflict, they may be impossible for anyone to discharge" (as quoted in Beitz 2009, 120).

Manifesto rights are often criticized for not being action-guiding. Beitz claims manifesto rights are action-guiding in the sense that they establish goals which help create the conditions that make it possible to both secure the right and therefore, also assign corresponding duties to the appropriate agents (Beitz 2009, 120). Beitz provides a possible defense of many of the difficult objections against human rights that can help arguments in favour of the human right to health. Beitz's human rights model was influential to Wolff's claims. However Wolff could have used Beitz's responses just discussed to respond to the objections raised by O'Neill and Sreenivasan and attempt a defense of the human right to health.

\subsubsection{Human Rights Doctrine: UN Declarations and Covenants}

The atrocities that occurred during World War II led to the creation of the Universal Declaration of Human Rights, adopted by the UN General Assembly on December 10, 1948. Protection from discrimination, including race, color, sex, language, religion, political opinion, property, and birth or other status (Article 2), was particularly important in the aftermath of the Holocaust as an attempt to prevent this from ever occurring again. The Declaration covered negative rights, such as rights to religion, opinion, thought and expression, to assemble and to associate, to participate in free elections and access to public office (Articles 18-21).

Positive rights were also introduced in the Declaration, though were not the main focus. Articles 22-30 of the Universal Declaration of Human Rights listed positive rights, 
such as: the right to social security to be enjoyed by everyone, just and favourable working conditions, protection against unemployment, equal pay for equal work, and the right to join a union (Article 23). Articles 25 and 26 specifically set out many of the positive rights that today we consider minimum needs for a decent life such as: the right to an adequate standard of living including food, clothing, housing and medical and necessary social services (Article 25) and the right to free education (Article 26).

The Universal Declaration of Human Rights was a significant statement at the time, laying down the foundations for what would need to become international human rights law. Binding covenants were needed in order for countries to sign on and commit to the newly created international human rights laws. The International Covenant on Civil and Political Rights (ICCPR) was first adopted in 1966, coming into full force by 1976. Most countries ratified this agreement in order to protect individuals from discrimination and persecution (OHCHR).

The second covenant created at this time, The International Covenant on Economic, Social, and Cultural Rights (ICESCR), was more controversial. Nonetheless, the ICESCR was a significant achievement for human rights. The international community for the first time recognized the idea that they had more than just a duty to not violate civil and political rights; they also had the duty to assist those in need. Social goods and services were recognized for the important role they played in maintaining the well-being of many in need.

Article 12.1 of the ICESCR contains the statement on the human right to health. "The States parties to the present Covenant recognize the right of everyone to the enjoyment of the highest attainable standard of physical health" (ICESCR Article 12). 
The right to health, as drafted in the Declarations and Covenants has been heavily criticized for being unrealistic, unattainable and hyperbolic. However, proponents of the human right to health approach use the Declarations and Covenants and their statements on social, economic and cultural rights as a starting point for their discussions on the importance of the right.

\subsection{Proponents of the Human Right to Health Approach}

This section reviews the three main approaches for the human right to health. Jonathan Mann (1998) and Paul Farmer (1999) provided the key claim that Jonathan Wolff uses in his argument for the human right to health. This core idea is that human rights and health are inextricably linked. Mann and Farmer also provide the case studies that Wolff uses in order to develop his negative right to health. This section provides a more detailed look at both Mann and Farmer's approaches and how Wolff used these core ideas to make his claims.

\subsubsection{Mann's Health and Human Rights Three-Part Framework}

The late Jonathan Mann's work on health rights focused on the discrimination and violations of human rights of those suffering from HIV/AIDS. He published a series of articles on the subject before his tragic death in a plane crash in 1998. Mann's goal was to link health and human rights in order to advance the well-being of human beings. He thought a detailed health approach should address all of the social determinants of health, i.e., claims to accessible health care services, clean water, sanitation, education, adequate housing and nutrition. He devised a three-part framework in order to demonstrate the 
relationship between health and human rights. This framework is meant to show that the two concepts are inextricably linked (Mann et al. 1999, 11).

The first relationship attempts to show that health policies impact human rights. The construction of policies, programs, and practices often impact oppressed groups, minorities, and can often be highly racialized. This relationship focuses on the impact of state power in the context of public health. Conversely, the second relationship is that human rights violations often have a direct impact on health. Violations to political and civil rights often have a negative impact on the physical, mental and social well-being of all individuals affected (Mann et al. 1999).

The third relationship restates that the promotion and protection of health is fundamentally linked to human rights. This relationship is evident through the first two linkages shown. Therefore, this intrinsic relationship must be recognized for its potentially dramatic consequences. Health is a precondition for an individual's capacity to enjoy their human rights and human dignity.

The importance of Mann's work was in insightfully highlighting the link between health and human rights. Mann was not a philosopher, and he did not provide us with a fully developed and normatively justified human right to health approach, however this key link could be of crucial importance to the formation of a justified negative right to health.

\subsubsection{Farmer's First-Hand Accounts of Health and Human Rights}

Paul Farmer also points out the link between human rights violations and public health in his work. As the title of his book, Pathologies of Power: Health, Human 
Rights, and the New War on the Poor suggests, Farmer views state power as a potential cause of disease. Those suffering from illness and in desperate need of secured health rights are most often the same people that the state oppresses. These are also the most at risk for human rights violations. He rightly points out that, while human rights should be considered universal, the risk of a human rights violation is not universal (Farmer 1999, 1490).

Farmer's analysis is based on his years of research and work as both doctor and anthropologist, through the organization he co-founded, Partners in Health (PIH). He gives detailed accounts of human rights violations that he has witnessed and how deeply this impacts health. His work primarily focuses on Haiti, as he has worked there as a doctor for decades. His work also helps us understand how the human right to health movement developed out of the HIV/AIDS movement, and the role that Haiti played in the development of the approach.

The relationship between the U.S. and Haiti was a crucial event in the development of Farmer's conception of the human right to health. After the political coup in Haiti in 1991, violence and upheaval within Haiti pushed thousands of Haitians to flee the country, seeking political asylum in other countries. While many had a clear case as political refugees, the U.S. illegally discriminated against the Haitian refugees. In the early nineties, more than 250 Haitian refugees were detained in a makeshift tent town on the United States Naval Base at Guantánamo Bay (Farmer 1999, 52). Sometimes called the Guantánamo HIV Camp, Haitians, some HIV-positive and some not, that were fleeing the violence in their home country were held at Guantanamo Bay. Haitians were redirected to the refugee camp because of the 1987 immigration law that barred HIV- 
positive immigrants from entering the country (Farmer 1999, 52).

The INS (Immigration and Naturalization Service) tested each refugee for HIV/AIDS before allowing them to pass in to the country and apply for political asylum. Ignoring public health laws, the Haitian refugees were forced to live in squalor for months with no privacy and no protection from the infectious diseases that their immune systems were too weak to battle. Despite warnings from other government departments about the potential impacts of an infectious disease on the camp, the INS refused to close the camp or treat the sickest of inmates (Farmer 1999, 53).

Farmer discusses the experiences of Yolande Jean, a refugee at the camp for 11 months. Her description of life at Guantanamo Bay for the Haitian refugees told stories of forced birth control shots, regular beatings, the burning of all the refugees' personal effects upon arrival, forced blood draws, and solitary confinements (Farmer 1999, 62).

By the time mass screening of all refugees was completed, the U.S. government had identified 268 HIV-positive refugees. Although Yolande and many others had already passed the stringent requirements for refugee status and were thus guaranteed asylum, authorities invoked U.S. immigration law to keep these Haitians out. In contrast, Cubans who hijacked planes to Miami or who arrived on U.S. soil by other means were not even tested for HIV, as Haitians were quick to point out (Farmer 1999, $59)$.

The contrast between U.S. public health policy and Cuban health policies demonstrates the dramatic difference that human rights violations can have on public health. The U.S., despite their strict quarantines and screening processes, were not able 
to effectively control the outbreak of HIV/AIDS. Discrimination against the Haitian refugees also meant that they were blocked off from accessing crucial medical treatment.

Cuba's policies were much less discriminatory. Although Cuba had mandatory testing and quarantined those diagnosed with HIV, there was no discrimination. Those in quarantine were given comfortable accommodations and round-the-clock medical treatment (Farmer 2005, 72). People were not scared to admit that they had been diagnosed with AIDS because there was no severe backlash and discrimination. They did not lose their jobs, or suffer any mistreatments, like those with HIV in the U.S. That coupled with an extensive country-wide education campaign resulted in Cuba's control of the outbreak. They were able to maintain the lowest levels of the disease in the Western world.

Farmer's approach is centered on the idea that most violations are rooted in "structural violence"- that is, social and economic inequalities determine who is subjected to rights violations (Farmer 1999, 1488). He discusses the link between structural violence and human rights violations, proposing what he calls "pragmatic solidarity", where public health and medicine can help the victims in ways that other professions cannot (Farmer 1999, 1491). It also allows for a separation from the reliance on governments for aid. Farmer wants to avoid a reliance on governments because he argues that governments are often the worst perpetrators of human rights violations.

Farmer, like O'Neill and Sreenivasan all agree that states do not seem to be the best choice as duty-bearers for the right to health. While the critics take a more pessimistic stance toward this problem, arguing that there is not anyone that can bear the moral duty, Farmer suggests an interesting approach. He argues that the medical 
profession and research universities may be able to help secure aspects of the right to health (Farmer 1999, 1493).

A 'health angle' can promote a broader human rights agenda in unique ways. In fact, the health part of the formula may prove critical to the success of the human rights movement. The honor in which public health and medicine are held affords us openings - again, a space of privilegeenjoyed by few other professions (Farmer 1999, 1491).

He argues this from his own practical experience working in developing countries that lack any health infrastructure, attempting to ground his theoretical ideas in his own day-to-day experiences with health and human rights. Farmer claims that doctors are in a unique position to be accepted when traveling to new countries and working with community-based groups to help develop institutions necessary to begin to fulfill the needs of the people. This is an aspect of what he calls pragmatic solidarity. Farmer himself managed to accomplish much in Haiti, the poorest nation in the western hemisphere. As Farmer points out:

Over the past decade and against a steady current of naysaying, we have channeled significant resources to the destitute sick in Haiti, Peru, Mexico, and Boston. We didn't argue it was 'cost-effective,' nor did we promise that such efforts could be replicable. We argued that it was the right thing to do. It was the human rights thing to do. Claims that we live in an era of limited resources fail to mention that these resources happen to be less limited now than ever before in human history (Farmer 1999, 1493).

Farmer suggests that universities and medical centers should conduct research and focus on educating all of the disciplines on health and human rights. In addition, 
universities should have complementary services, such as medical services, "making services - pragmatic solidarity — central to the work of health and human rights programs" (Farmer 1999, 1492).

Farmer's view attempts to take away a dependence on governments as the ones to implement rights. Instead he promotes a combination of universities, the medical profession, community-based groups, and nongovernmental organizations working collaboratively to secure health and human rights.

In the end, university and hospital-based programs may hope to be, along with the efforts of nongovernmental organizations, independent, well designed, pragmatic, and feasible. The imprimatur of medicine and public health would afford even more weight and independence. And only a failure of imagination has led us to ignore the potential of collaboration with community-based organizations and with communities in resistance to ongoing violations of human rights (Farmer 1999, 1493).

This is not to entirely exclude governments. Farmer's emphasis is just to extract the human rights movement from solely relying on states in order to accomplish anything. If a government would be willing to collaborate with the other institutions mentioned in order to work toward the human rights goals, Farmer would not object (Farmer 2002, 664). 


\subsubsection{Wolff's Philosophical Account of the Human Right to Health Approach}

Wolff spends the majority of his book (2012a) discussing cases that he has pulled from Farmer's work over the years as well as other sources, such as Mann's discussions of the AIDS movement in the U.S. during the 1980's. I argue in my paper that Wolff does this in order to demonstrate the effect that the violation of negative rights has on health and hence to provide a non-cosmopolitan, negative justification for health as a human right. The HIV/AIDS pandemic is used by Wolff as his main example in highlighting the link between health and human rights (Wolff 2012a).

Wolff traces the history of Mann and Farmer's human right to health approach, which developed out of the AIDS movement in the 1980's. HIV/AIDS was first identified and reported in 1981 in the US. The US health system had eradicated many major infectious diseases over the course of the $20^{\text {th }}$ century, and being suddenly faced with a new fatal disease shocked the world. The details of where AIDS came from and how it was transmitted were still unclear at this point. The fear surrounding the new disease created the environment for a severe backlash against those infected. The groups that were first primarily impacted by AIDS were referred to as the "four H's"homosexuals, heroin users, hemophiliacs, and Haitians. This also sometimes included a fifth "H", hookers. (Wolff 2012a, 42) Other than hemophiliacs, these were groups that were already highly stigmatized and discriminated against. The AIDS scare caused even more overt discrimination against these groups.

The discrimination had a severe impact on the country of Haiti, already the poorest country in the Western hemisphere. Haiti lost millions of dollars and countless jobs because of tourist boycotts and lost exports (Farmer and Kim 1991, 208). The 
Haitian immigrants in the U.S. did not fare better, as they were targeted by attacks, lost their jobs, and were evicted from their homes. This discrimination was even directed toward Haitians that were not HIV-positive, as they were perceived to be carriers of the disease (Wolff 2012a, 42).

The gay community, one of the first groups that were severely impacted by the AIDS epidemic, also faced extreme discrimination. Just as AIDS was sometimes referred to as the "Haitian Disease", it was also called the "Gay Disease" or the "Gay Plague". Instead of sympathy, the public instead chose to blame the victims, perceiving them as having brought the disease on themselves.

Even in the early 1980's we can detect connections between human rights and HIV/AIDS. Early speculation was that AIDS was the result of the promiscuous gay lifestyle of bathhouses and drugs. A type of moralistic "if they behave like that what do they expect?" led to popular support for severe restrictions on homosexual behaviour (Wolff 2012a, 42).

HIV/AIDS became a human rights issue for the first time because the gay community came together and fought back against the mistreatment of people living with AIDS. While this is now commonly done for a variety of diseases, it was a first for the early years of HIV/AIDS (Wolff 2012a, 42). Many new groups emerged that were promoting gay rights, safe sex, and supporting people living with AIDS with medical support as well as support for securing their civil and political rights. This included the group AIDES, which was founded by Daniel Defert whose partner, Michel Foucault had died of AIDS in 1984 (Wolff 2012a, 48). The work of these groups helped shift the general treatment of those living with AIDS. The Denver Principles, a human rights charter outlining the rights of people with AIDS created by the movement greatly 
influenced the GIPA Principle - Greater Involvement of People Living With HIV/AIDS, which was created at the 1994 AIDS summit in Paris (Wolff, 2012a, 50).

As Wolff points out, the HIV-AIDS crisis highlighted a central moral dilemma in human rights and public health. At times protecting the rights of those inflicted with an infectious disease will seem to be at odds with protecting the rest of society from contracting the infectious disease. The difficult task of balancing the rights in order to protect society without infringing on the rights of those who are already sick was the central task for which the human rights/AIDS movement had to find an answer. As Mann first pointed out, human rights had to be taken into consideration if public policy was going to get a handle on infectious disease.

For in the mid-to late 1980s it was realized that unless the civil rights of people living with HIV/AIDS were protected, public health was at risk. People would not take tests if they feared that a positive result might be released or leaked to family, neighbors, employers, or insurers. This led, according to Jonathan Mann, for the first time, to the game changing idea that preventing discrimination must be intrinsic to public health programs, as well as to a recognition that weak support for human rights for sex workers, illegal immigrants, the poor, drug addicts, and young homeless people itself became a risk factor for HIV infection (Wolff 2012a, 52).

Despite AIDS starting off as a disease that affected the affluent travelers, it rapidly moved toward a disease that primarily affected the most severely marginalized of society. It is these groups for whom the protection of their human rights can make the biggest difference.

As I previously argued, Wolff uses the history of the HIV/AIDS pandemic and Famer and Mann's cases in order to make a case for the negative human right to health, 
although he does not realize this. Instead of focusing on fulfilling a positive right to health, he focuses on the duties of states in respecting and protecting the human rights of their citizens. Currently in the right to human health debate, there is a large gap in the literature that my paper attempts to address. Wolff claims to be constructing a normatively justified account of the human right to health approach, but does not manage to do so. However a development of Wolff's work that pieces together various claims that he makes, as I have attempted in my paper, can demonstrate that the human right to health approach can be normatively justified by a focus on negative rights.

\subsection{Critics of the Human Right to Health Approach}

The concept of the human right to health is heavily criticized, making it extremely difficult to provide an adequate normative foundation for the human right to health. The two most prominent objectors to this approach are Gopal Sreenivasan (2012) and Onora O'Neill (2005). Their objections focus on the lack of a normative foundation in a positive human right to health approach. Sreenivasan and O'Neill both claim that we cannot identify whose duty it is to secure the human right to health. Without an identifiable duty-bearer, the human right to health is incoherent. This section takes a detailed look at both Sreenivasan and O'Neill's arguments. It also considers another objection not addressed in my paper, the resource allocation problem. Sreenivasan and O'Neill raise this concern, as well as Elizabeth Fenton and John Arras (2009), whose argument I introduce here. This objection states that a human rights framework is too abstract to give the information needed in deciding concrete details such as costs or in deciding 
priorities of policy. This objection is not as damaging as the objection I focus on in my paper; however, it is another common concern in the human right to health literature.

\subsubsection{Sreenivasan's Argument from the Nature of Health}

Sreenivasan and Wolff are prominent figures currently debating the human right to health. Sreenivasan has many objections to the right to health, most of which are not adequately addressed by Wolff. This section will provide a detailed account of Sreenivasan's main arguments.

Sreenivasan sets up two main examples in order to detail what he calls his "Argument from the Nature of Health". This argument attempts to show that the state cannot bear the correlative duty of an individual claim-right to health because the content of the right does not match the content of the obligation. He uses Switzerland as an example presumably as a country that can afford the costs involved in securing health rights to its citizens, which avoids any of the cost objections and provides a basis for analysis of the right to health. For his example, he assumes that "for each Swiss citizen, the Swiss state has a moral duty to spend an equal per capita share of its normative health budget to preserve his or her health ... the Swiss state has a moral duty to spend the 'rightful individual share' on each citizen's health" (Sreenivasan 2012, 250-251).

Sreenivasan points out that a complete view of health includes both the social determinants of health (such as education, income and job control) and various components of public health (such as sanitation, vaccination and vector control) (Sreenivasan 2012, 251). Sreenivasan chooses one of each as his examples, education and vaccination. 
Sreenivasan's first example is education. Studies have shown that better educated individuals are healthier. In fact, higher education seems to directly result in higher life expectancies (Sreenivasan 2012, 251, Sreenivasan 2007). Given these statistics, Sreenivasan then claims that maximizing the life expectancy for a random Swiss citizen therefore would also require spending a certain amount of their health share on their education. This would be a separate cost from whatever would be rightfully spent on their education. Sreenivasan argues that the Swiss state is not actually required to spend any health bonus on a citizen's education because "the distribution of education is subject to its own requirements of justice. However, short of a giant coincidence, the distribution of education sanctioned by principles of education will not also maximize health as an instrumental side effect (Sreenivasan 2012, 252).

However Sreenivasan's argument seems to approach the distribution of spending rather unrealistically. It would seem that a just distribution of education could also maximize health without additional spending. If we agree that education is important in and of itself, as well as important to an individual's health, health policy would dictate that the budget for education be taken seriously. This would mean providing enough resources to ensure as much education as possible under a country's resource constraints. Education is already seen as something valuable to invest in for many other reasons, it is just now shown to also be beneficial to health. That does not mean a country needs to spend more on education just because it helps the health of individuals, it just means that they should ensure that they are spending according to education's own requirements of justice. 
This would also apply to Sreenivasan's second line of argument in his education example. The argument states that it would be an administrative nightmare to require the Department of Education to attempt to deal with the effects of education on any secondary outcomes (such as its effect on health) when setting its budget, evaluating its priorities, and so on. Sreenivasan concludes "to avoid this nightmare, the state is permitted simply to ignore such secondary effects, which means that no additional spending on education will be implemented" (Sreenivasan 2012, 252). Using the same line of reasoning again, this conclusion seems to be entirely unnecessary. Right now in Canada, citizens have equal access to education through secondary school, and access to subsidized post-secondary education. As the correlation shows, Canadian citizens' health is being benefitted as we speak by a country that budgets for education, valuing education in and of itself. There is no need to give extra resources to education just because it benefits health. As well, there is certainly no need for education sectors to monitor health. They are separate domains.

Sreenivasan concludes that on his picture, the Swiss state does have a moral duty to preserve the health of each citizen.

Moreover, the state's per capita health expenditure is constrained in just the way a human right to health requires (by the rightful individual share). Yet, for all that, the state is not required to spend that share as the right requires. Specifically, the state is not required to maximize the individual's health under the constraint given by their rightful share. Hence, the content of the state's duty to preserve the individual's health diverges from the content of the individual's putative right to health. Intuitively, the divergence is sufficient to show that the Swiss state's moral duty does not correlate with the human right to health Swiss citizens are supposed to 
have. In other words, the Swiss state does not owe its moral duty to its citizens (Sreenivasan, 2012, 253).

According to Sreenivasan, if the content of a state's duty is different from the content of a person's right to health, this means there is no correlation and therefore the right cannot exist. He fails to detail why exactly a correlation must mean that the contents are an exact match. It seems plausible that an individual may have a right to health that entails certain claims, and that this may result in entirely different obligations that are necessary in order for the right claim to be fulfilled.

Sreenivasan weakens his claim, discussing whether or not there would need to be at least some additional education spending for some, if not all, Swiss citizens. He assumes that maximizing the health return for a random Swiss citizen requires some additional education spending for her. But is it enough to assume that this is true for some citizens, rather than for all or most? Even a requirement for extra spending for some citizens conflicts with both the justice in education and convenience in administration arguments. He thinks this strengthens his argument. However his argument seems to be overly focused on individual education maximization. Spending an overall fair share on education for the whole population will allow for such variances as spending more for one individual and less on others. Where one individual will need more spending, another will need less. His argument does not address this (Sreenivasan, 2012, 253).

According to Sreenivasan's second example, there are two different routes by which vaccinations protect individuals against diseases. There is the direct route, where vaccinating an individual protects that particular individual by providing immunity 
against a given infectious disease. The indirect route is when vaccinating an individual protects other individuals by reducing the chance that they will come into contact with the infectious disease. This is to achieve "Herd Immunity", which is achieved:

If a sufficiently high proportion of individuals in a given population has personal immunity against a given infectious disease, then the likelihood of someone who is not immune contracting the disease becomes negligible, since the immunized function as a protective barrier against transmission. To achieve herd immunity requires a proportion of personal immunity (and hence, vaccination) in the population - the more infectious the disease, the higher the proportion required (Sreenivasan, 2012, 255).

Sreenivasan is interested in the indirect route for his purposes. Assumed, for his example, is that the Swiss state has a moral duty to spend the 'rightful individual share' on preserving each citizen's health. On what he believes is the very plausible assumption that providing herd immunity against diphtheria for example is cost-effective, it would then follow that providing this would be the Swiss state's moral duty to preserve each citizen's health. Once again, the specific issue for Sreenivasan is whether the Swiss state owes its moral duty, in this example to provide herd immunity against diphtheria, to its citizens individually.

Sreenivasan contrasts this with the alternative; does a Swiss citizen's moral human claim-right to health mean that they have a claim-right to the existence of herd immunity in Switzerland against Diphtheria? The answer for Sreenivasan is no for the reason that no individual can have a moral claim-right to a pure public good such as herd immunity. Intuitively, he finds this reason very compelling. 
On the one hand, the Swiss state's moral duty to preserve the health of each citizen entails a moral duty to provide the public good of herd immunity against various contagious diseases. On the other hand, a given Swiss citizen's putative moral human right to health does not entail a claim-right to any such public good. This difference in their entailments establishes, once again, a divergence in content between the Swiss state's duty to preserve the health of each citizen and an individual claim-right to health. In turn, this means that the Swiss state's moral duty is not owed to Swiss citizens individually (Sreenivasan, 2012, 258).

Sreenivasan's second skeptical argument was presented with his two examples: education and vaccination. He attempted to show that if we are viewing the right to health realistically, with all the factors involved, it goes too far beyond what an individual can rightfully claim. What is within the scope of an individual's claim-right to health "is limited to the conjunction of 'patently health' factors and 'strictly individual' factors. By contrast, we have seen, some of the causal factors necessary to maximize individual health are not patently health factors (e.g. education) and others are not strictly individual factors (e.g. public goods, such as herd immunity)" (Sreenivasan 2012, 259). Because of this, an individual claim-right to health sometimes demands too much and other times demands too little. Sreenivasan claims that the right to health demands too much from the social determinants of health, since these are also already covered by other principles of justice and are therefore not only controlled by a right to health. It demands too little, or nothing at all, from public health policies that produce public goods, since these causes fall beyond a right that an individual may claim. Therefore, he concludes that any moral duty the state may have to preserve the health of individuals "is justifiably aligned in 
relation to the causes of health, it simply cannot be the correlative of an individual claimright to health" (Sreenivasan 2012, 259).

\subsubsection{Sreenivasan and O'Neill: The Allocation of Duties}

O'Neill (2005), another prominent figure in the debate on health as a human right, also does not support human rights obligations being borne by the state. O'Neill claims that states are not always capable of fulfilling these duties. Furthermore, O'Neill rejects Wolff's state-by-state approach as incapable of achieving international justice. She claims that domestic justice will always be the focus of states; therefore political philosophy should focus on a more cosmopolitan account. O'Neill's view is that we need to be both more practical in the identification of health policy norms that can guide action without minimizing public health and without the arbitrary assumption that it is the domain of the state to secure the health of its citizens (O'Neill 2002, 40).

The human rights account could fit her criterion, however O'Neil finds it problematic. Specifically, she finds rights language such as, "a right to life", "right to access" and the like problematically ambiguous. The ambiguity cannot be sorted out without being able to specify the obligations that correspond to the interpretation of the rights (O'Neill 2002, 42). As the state is either unwilling or incompetent at securing the duties to a right to health as O'Neill claims, she advocates for a view that starts from a systematic account of obligations rather than of rights. A focus on required action rather

than on rights claims to receive makes it easier to spot incoherence. O'Neill's claims that it is easy to talk about a universal "right to health" but easy enough to see that when we 
attempt to consider who has to do what for whom that universal health cannot be provided, therefore there cannot be a right (O’Neill 2002, 42).

O’Neill proposes what she calls a "minimalist Kantian conception of reason and action that can establish basic obligations to reject coercion and deception, victimization and oppression, and to assist others in permissive forms of action-hence specifically to support others' health" (O’Neill 2002, 42). She argues that these obligations, although not fully specific either, are clearer in determining who holds the obligations compared to an account that derives the obligations from rights. In O'Neill's account,

Some obligations fall directly on all agents, others fall indirectly on all agents in the form of obligations to support the construction and maintenance of effective practices and institutions that allocate obligations to identifiable agents and agencies. The need for an internally coherent allocation of obligations, including transborder obligations, is more explicit, hence more readily addressed than it is in rights-based accounts of justice (O’Neill 2002, 42-43).

O’Neill's view designates that basic obligations fall on all agents and all institutions. These obligations are then made more specific by constructing institutions and cultures that allow for the effective allocations of obligations and by developing the necessary capabilities. Her process for establishing health policies starts from the actual configuration of agents and institutions and their capabilities.

The most effective agents of justice may therefore be different bodies and different institutions in different situations. In some situations an international institution or a certain sort of nongovernmental organization (NGO) or a religious group, a women's group, or even a multinational corporation may be able to take an effective role in improving health. One 
agent or type of institution will not always be the correct one, it will vary according to context (O’Neill, 2002, 44).

O'Neill claims that her Kantian minimalist account is a clearer way to identify the obligation holders - by starting from the obligations rather than the entitlements. However the identification of "agents of justice" in her view is problematic. Part of her justification for starting her theory at the obligations themselves is that she wants to skip right to the discussion of who it is that is available to help promote health, and what are their immediate capabilities. This is an interesting idea, however, she does not explain how this would be possible without identifying clearly what is needed in the first place. Obligation identification is only helpful if we know what the obligation is trying to accomplish. She takes the obligations out of human rights discourse, but by leaving out the actual right claims there is nothing to explain why we are doing what, for whom.

O'Neill believes that this minimalist Kantian conception of reason and action is better suited to address global health needs. O'Neill's primary concern as discussed in the first section is that human rights can only be considered universal if their corresponding obligations are also universal. O'Neill claims that this is not the case when it comes to social, economic and cultural rights, which includes the right to health. The corresponding obligations of social, economic and cultural rights are not universal, according to O'Neill, and a human rights model does not appropriately show us who should bear the obligation if it is not everyone that should bear the obligation. O'Neill concludes that the human right to health is an institutional right, not a universal human right. For O'Neill then, the human right to health is not a human right, but should be considered more of a manifesto right. (O’Neill 2005, 432). 


\subsubsection{Fenton and Arras: The Resource Allocation Problem}

Fenton and Arras raise a similar criticism against the human right to health as O'Neill in their 2009 article "Bioethics and Human Rights: Access to Health-Related Goods". They argue that the only plausible conception of human rights is the institutional conception.

A human right to health-related goods entails only a right to institutions that will provide procedures for determining who should get what in a context of scarcity and pluralism regarding values and priorities but that the decisions made within these institutions should reflect the values of the ideal conception of human rights. Concrete or effective rights to health and health-related goods will thus depend on particular institutions within particular sociocultural contexts and will have to be responsive to varying degrees of scarcity and different health-related priorities in different states (Fenton \& Arras 2009, 36).

Fenton and Arras reject two other conceptions of human rights to health-related goods in favour of the institutional conception. The first account of human rights they consider is the Demand-Side Conception. The example of this approach used is the Covenant on Economic, Social and Cultural Rights that states in Article 12 a universal human right to the "highest attainable standard of physical and mental health". In this type of statement we can see an overemphasis on a demand side to rights claims. Fenton and Arras argue a statement such as this is clearly ignoring the supply side to this claim. The supply side includes all of the obligations, duties and costs that correlate with the right. An obligation to secure the claim must be taken as seriously as the right itself. 
"And the burdens they impose on others must not be viewed as unreasonable or excessively burdensome (Fenton \& Arras 2009, 31).

The second human rights account rejected by Fenton and Arras is the Ideal Conception of Human Rights. This approach has what they consider to be a more realistic conception of the supply side of human rights. The Ideal Conception focuses on a few human interests that are considered to be fundamental for human dignity. Under this approach, it must be at least possible to assign the obligations necessary for the fulfillment of the human interests.

Such a conception would be fairly capacious, encompassing both traditional civil and political rights and a robust set of welfare entitlements to services such as education and health care, but it would have to pass the criterion of universal reach in order to keep things basic and avoid the problem of endlessly proliferating rights (Fenton \& Arras 2009, 31).

What their main issue seems to be with the ideal conception of human rights is that it does not provide enough information to help allocate resources in a resource-scarce world. At best this conception can point us toward the institutions that are necessary to begin to fulfill the rights claims. It cannot help with the complex decision-making that is involved in choosing certain policies over others, or determining where resources need to be distributed. The issue with this particular conception does not actually seem to be a lack of universal reach, but more so a resource allocation problem.

Fenton and Arras believe an Institutional Conception is needed in order for human rights to taken seriously. This approach requires basic domestic institutions be established, such as "educational systems, police, land reforms, and the empowerment of women" (Fenton \& Arras 2009, 34). These would be preventative institutions that would 
help minimize the likelihood of human rights violations from occurring. If these preventative institutions fail, Fenton and Arras advocate for what they call "back-up institutions, like national or regional courts, international and NGO service providers, charitable organizations, and, as a last resort, military force" (Fenton \& Arras 2009, 34). These institutions would serve as a way to match human rights with their corresponding obligations in order to secure rights as well as provide a place for democratic discussions of the content of the right and how best to secure the rights.

The distinguishing factor separating human rights from civil, political, or liberal rights for Fenton and Arras are that human rights are not supposed to be dependent on any particular social, cultural or institutional context for their existence.

If the ideal conception of human rights must be embedded in an institutional conception in order for human rights to become truly effective and action guiding, and if the institutional conception will yield conclusions relative to degrees of scarcity and particular health-related priorities of particular cultures and states, then such institutional human rights cannot be ascribed to us simply on the basis of our humanity, and we must conclude, contrary to our usual way of speaking, that they do not have universal reach (Fenton \& Arras 2009, 35).

If human rights must be embedded in an institutional framework, then Fenton and Arras' concern is that these institutions will vary from nation to nation. Each country will have their own institutions that are both influenced by the resources that they had available and influenced by the different priorities that they as a country have decided should be their focus. This relativity, according to Fenton and Arras makes it impossible 
to claim that the human rights could be considered to be universal. They conclude that institutional rights cannot be considered to be human rights in the traditional sense.

Thus, although specific human rights claims emanating from differing institutional contexts will not, strictly speaking, be grounded solely on appeals to our common humanity and enjoy universal reach, they will be tethered to institutions that are, in turn, charged with the task of making ideal human rights real and effective in concrete circumstances (Fenton \& Arras 2009, 36).

Fenton and Arras do not think that institutional rights are actually rights with corresponding entitlements. They use Norman Daniels's hypothetical situation in order to show that institutional rights do not confer actual entitlements to health-related goods. Their claim is that institutional rights actually resemble policy judgments rather than standard rights claims (Fenton \& Arras 2009, 33).

Daniels's hypothetical considers a poor country that is trying to improve maternal and child health. There are various ways that the poor country can attempt this, and there are many possible policy options available to them. For example, as Fenton and Arras mention, the government can focus on different forms of education for women about what is available to them to improve their health, such as the importance of midwives. Governments could focus on providing access to health care in rural areas, on secondary education for girls and relatedly on changing norms that encourage early marriage. (Fenton \& Arras 2009, 33). We have the one value represented by all of these possible actions, which is to improve maternal and child health. Each policy listed supports this endeavor. This raises the question for Fenton and Arras, whether the women or children affected by any of the possible policies that are implemented could be said to have a 
greater entitlement over the women and children affected by the implementation of another of the policies from our list of choices. It would seem that all can claim an equal entitlement from institutions obligated to secure their right to health-related goods.

Fenton and Arras conclude that a human rights framework is just too abstract to deal with the concrete details such as costs, and deciding priorities of policy. Considering rights to be "human rights" does not mean that they have universal reach. Fenton and Arras allow for the idea that institutional rights may be tethered to human rights but claim that while many believe that because human rights are involved, both ideal and institutional conceptions of human rights must have universal reach. This is not the case for Fenton and Arras, who conclude that rights to health-related goods will ultimately always be economically and culturally relative, lacking universal reach (Fenton \& Arras 2009, 37).

\subsection{Theories of Global Health}

This section covers more prominent global health approaches, other than a human rights approach. These approaches were not included in my paper, but are necessary in completing the discussion on global health rights. Norman Daniels (2008), constructs a Contractarian theory of distributive justice for health care needs. Although his approach is not used in my argument, as a leading figure in health rights discussions it is a relevant approach to review. Also addressed in this section is Allen Buchanan, whose 2009 Justice and Health Care: Selected Essays, consists of a collection of his work, spanning decades, in health rights. Buchanan uses a cosmopolitan framework to determine the concrete responsibilities involved in fulfilling a positive right to health. He follows 
Shue's conception of a moral division of labour, using institutions as the means for everyone to fulfill their cosmopolitan duties.

As I will point out throughout this section, there are aspects of Buchanan's arguments that Wolff could have used to help support his claims; however, as Wolff did not use Buchanan's work, and I argued that Wolff's approach was a non-cosmopolitan view of the negative right to health, Buchanan's work was not directly relevant to my paper.

\subsubsection{Buchanan and Hessler: Specifying the Content of a Human Right to Health} Care

Current literature on the human right to health has moved away from defining health rights as simply a right to health care. Instead, health care is considered to be just one of the many social determinants of health, that also include things like adequate food, housing, just wages, and education. Allen Buchanan and Kristen Hessler, in their 2002 article "Specifying the Content of a Human Right to Health Care", explore this trend, and attempt to define the content of a human right to health.

Buchanan and Hessler point out that health rights are complex goods, with a broad range of factors that affect the fulfillment of the right to health. This is why the term right to health is more appropriate than the previous term, a right to health care. While this change accurately demonstrates the fact that there is more to a right to health than simply access to medical services, this new term also makes it seem quite demanding. A right to health can incorrectly be taken to mean a right to be healthy which is an impossibly high standard. 
For Buchanan and Hessler, the right to health serves as an indicator of the basic human interest in at least a minimal level of health, and that this is important enough to justify an obligation to fulfill this interest. According to Buchanan and Hessler, each of the important social determinants of health is to be considered one part of the many parts that make up the right to health. They are separate claims that are justified by referring to the basic human interest in health (Buchanan 2009, 206).

Buchanan does not believe we should use an argument from universality to justify a human right to health. Instead, in his 1984 paper "The Right to a Decent Minimum of Health Care", he advocated for a pluralistic approach that involves the combination of four different arguments: 1. An argument from special rights; 2. An argument from the prevention of harm; 3. Prudential arguments; and 4. Two arguments for enforced beneficence (Buchanan 2009, 27).

Buchanan's argument from special rights is in response to the argument that health rights must be universal. Special right-claims, instead confine the right to specific individuals or groups (Buchanan 2009, 27). There are three arguments that could possibly justify individuals or groups claiming special rights.

1. In order to rectify past or present institutional injustices.

2. As compensation to those who have suffered unjust harm, or have been exposed to health risks as a result of the actions of private individuals or corporations

3. For those who have undergone exceptional sacrifices for the good of society as whole (For example, injured military, police, etc.). (Buchanan 2009, 27) 
Buchanan's second argument in his pluralistic approach is called the arguments from the prevention of harm. This argument states that once a case has been made to spend on public health measures, there is a moral and constitutional obligation to ensure a common standard of equal protection from harms. Public health services, according to Buchanan should not vary across racial, ethnic or geographic groups within a country. This argument could be elaborated on to be similar to a universal right to health argument, however, Buchanan's argument from the prevention of harm is applied to domestic public health services, rather than a cosmopolitan global universal health standard (Buchanan 2009, 27).

Buchanan's prudential arguments are the third part of his pluralistic approach. This argument emphasizes certain benefits to securing a right to health rather than focusing on the harms that would occur without the right. A prudential argument could claim that a population with their basic health needs met amounts to a more productive workforce. This argument does not assume a moral right to health, it simply argues that it could be prudential and in the best interests of the country to have a healthier population (Buchanan 2009, 27-28).

Finally, Buchanan also provides two arguments from enforced beneficence.

1. People would rather maximize their small contribution of charity than contribute to a larger common goal that is only to achieve a decent minimum

2. The Assurance Problem - rational beneficence requires assurance that enough others will contribute. Therefore a solution would be to create a coercive mechanism that penalizes non-contribution. A mechanism such as this would be able to coordinate charitable efforts and allocate resources effectively. (Buchanan 2009, 30-31) 
Buchanan's pluralistic approach is meant to cover any possible justifications, moral and prudential. However, it ends up seeming overly complicated and confusing. While he stretches out arguments broadly to attempt to cover everything, he seems to miss points needed in order to properly justify the right to health. An argument from special rights, similar to Pogge's cosmopolitan approach would claim that essentially all individuals in the developing world are owed compensation for past harms during colonial conquests or present harms created by the globally unjust system. However, Pogge attempts to justify this claim, by showing how the developing world has been harmed or is currently being harmed by global institutions; Buchanan does not do this in his argument, therefore his claim seems unjustified. It also does not mention the people it seems to exclude. Many people in need of health rights might not be able to claim past or present harms, such as people in affluent countries that cannot be considered to be a part of any oppressed or vulnerable group.

Similarly, Buchanan's argument from enforced beneficence would first need to justify such a coercive mechanism. Considering the difficulty a country like the U.S. has in agreeing on some sort of nation-wide health system, it would seem unlikely that the U.S., or another country that has resisted universal health benefits for their population, would agree to what is essentially an extremely large redistributive tax meant to afford health care services to those that cannot afford them. While Buchanan's work is extremely helpful in exploring the content of a health right, his attempt to provide a solution and justification for health rights is not satisfactory. 


\subsubsection{Buchanan and Matthew Decamp: Responsibility for Global Health}

Although Buchanan's pluralistic account of health as a human right has some problems, Buchanan and Matthew Decamp's 2006 article, “Responsibility for Global Health", has many interesting points that Wolff should have made use of in his discussions of the human right to health. Buchanan and Decamp take aim at O'Neill and Sreenivasan's main objection to the right to health: that the human right to health is incoherent because we cannot identify the bearer of the obligations to fulfill this right. Buchanan and Decamp argue that we should move away from thinking that we need to provide concrete answers to every global health problem, and specify conclusions about who should do what to solve these problems (Buchanan 2009, 220). They raise an interesting concern that they term "duty dumping".

To "dump" a duty in global health means to ascribe obligations to individuals or institutions, holding them accountable for the adverse health effects of their policies, without offering adequate justification for why particular obligations would be imposed on particular individuals or institutions. The thought might be that the putative obligation is too onerous or that it has been assigned to the wrong entity (Buchanan 2009, 220).

The idea of duty dumping is meant to ensure that certain institutions are not unjustifiably saddled with all of the responsibilities of providing some sort of good that is necessary for the right to health. The example Buchanan and Decamp provide is the distribution of expensive, lifesaving, antiretroviral drugs for HIV/AIDS patients that cannot afford them. Buchanan and Decamp claim that the responsibility for providing these drugs to those that cannot afford them are often dumped on pharmaceutical 
companies. This duty is considered to be more than just a moral obligation to provide something. Buchanan and Decamp claim that the duty is much more demanding. Pharmaceutical companies are seen as doing something morally wrong if they do not do absolutely everything possible to make the ARV's affordable. This, according to Buchanan and Decamp is "duty dumping"; an unjustified, very demanding obligation unfairly ascribed to individuals, private corporations or institutions (Buchanan 2009, 223).

In addition to "duty dumping" being morally unjustifiable, Buchanan and Decamp claim that it provides political cover for institutions that do have justifiable moral obligations and are failing to fulfill them. In particular, they will argue that focusing on unpopular private organizations like the big pharmaceutical companies hides the fact that states are failing in their responsibilities to their citizens (Buchanan 2009, 223).

Buchanan and Decamp suggest that a satisfactory account of determining concrete responsibilities in health must do three things:

1. It should correctly identify existing determinate responsibilities for health "rather than simply foisting imagined determinate responsibilities on whatever resource-rich agents are conveniently at hand--Duty Dumping".

2. It should recognize that in many cases determinate responsibilities will involve the creation of new institutions and the modification of those that already exist.

3. It must make clear that the responsibility for holding powerful agents accountable lies with everyone and especially those with resources and political authority (Buchanan 2009, 223). 
Buchanan and Decamp argue that from a cosmopolitan perspective, there are two sources of moral concern about global health: the obligation to ensure access to institutions that protect their basic human rights, and the imperfect obligation of humanity or benevolence. Following Shue's line of argument in "Mediating Duties", Buchanan and Decamp think the best way to accomplish these obligations is through a fair and effective moral division of labour — best achieved through the creation and use of institutions. Alone, individuals cannot do much to fix global health problems, however a coordinated effort through institutions can accomplish global obligations. The institutions would then assign determinate duties to an array of individuals occupying various institutional roles (Buchanan 2009, 223). Institutions are needed to ensure universal access to just institutions, to collect the necessary resources and distribute them fairly, and to enforce the fulfillment of the duties created by the institutions (Buchanan 2009, 224).

Buchanan and Decamp, while raising interesting points that should definitely be included in global health discussions, still fail to address the concerns that O'Neill and Sreenivasan have with a cosmopolitan foundation for the right to health. Even if we make use of institutions in order to assist everyone fulfilling their global duties for health, there is still the problem of creating the fair and effective moral division of labour. Who will decide what is fair and which institutions need to be created in order to accomplish what? This is not clear in Buchanan and Decamp's account.

\subsubsection{Norman Daniels: Normal Opportunity Range in Health}


Norman Daniels's approach uses the Rawlsian principles of justice as fairness in order to construct a theory of distributive justice for health care needs. Although his approach is not used in my argument, as a leading figure in health rights discussions, it is also a relevant approach to review. His account is centered on the idea of the "normal opportunity range" of a given society. He argues for the importance of health because it restores "normal species functioning" (Daniels 2008, 42). He links the two concepts by claiming that impairments in normal species functioning reduce the range of opportunities available to individuals. These opportunities are what individuals use to attain whatever their conception of the good may be. Restoring normal species functioning, and in turn, ensuring the range of opportunities, is more than just access to health care for Daniels. He recognizes that a theory of health must also include "an appropriate distribution of other social determinants of health" (Daniels 2008, 43). This

might include access to clean water, sanitation, appropriate housing and work conditions, and education.

Buchanan has criticized Daniels's account, claiming that restoring normal species functioning does not guarantee a universal right to a decent minimum of health care. Daniels does not specify whether we should be focused on putting all of our resources into narrowing the distance between the opportunity range of the worst off in society and the normal opportunity range or if we should be dividing the resources equally among all of those that fall short of the normal opportunity range (Buchanan 2009, 26).

\subsection{Theories of Global Justice}


This section reviews a range of topics that provide a background to some of the most influential theories in global justice and development ethics. These approaches very often inform the concepts and principles used in global health theories. John Rawls's $(1971 / 2005,1993 / 2005,1999,2001)$ extremely influential theories of justice have widely impacted most, if not all of the literature in global justice and health rights. Thomas Pogge (2008), originally constructed his view as an extension of Rawls's national theories of justice. Pogge's view is a central cosmopolitan theory, and is used in my paper in order to differentiate Wolff's view from a cosmopolitan approach to health rights. This section examines Pogge's theory in more detail. Lastly, this section also examines Amartya Sen $(1999,2009)$ and Martha Nussbaum's $(2006,2011)$ capabilities approach. Although not entirely relevant to the negative right to health focus of my paper, Sen and Nussbaum's views have informed much of the current health rights literature, particularly by contributing important information on poverty, development, and the importance of a complex view of the social determinants of health.

\subsubsection{Rawls: Global Justice and Redistribution}

John Rawls's global justice theories originate from his views of a justly structured democratic liberal state (Rawls 1971/2005). He focuses on the structure of domestic institutions as the basis for achieving background fairness. The institutional structure is the means for ensuring that the benefits and burdens are fairly distributed within a nation. In a well-ordered society, individuals would have the best chance to realize the effects of his two basic principles of justice, which, behind his famous veil of ignorance, Rawls believes all reasonable individuals would agree are just (Rawls 2001, 42-43). 
The first principle of justice is one of liberty, where all citizens of a nation are to have equal rights to basic liberties and the freedom to pursue their conception of the good. Rawls's second principle of justice ensures fair equality of opportunity. "Social and economic inequalities are to be arranged so that they are both (a) to the greatest expected benefit of the least advantaged and (b) attached to positions and offices open to all under conditions of fair $\square$ equality of opportunity" (Rawls 1971, 72).

All citizens are to be able to pursue an education and a chosen career path, again, regardless of their initial background. This principle requires that social institutions should be shaped in order that all persons, irrespective of social or economic class, race, and gender, have roughly equal chances for political involvement in decisions that affect their life. This principle also entails what Rawls calls "the difference principle", which is that any inequalities within a society are only justifiable insofar as they are to the benefit of the least advantaged (Rawls 1999, 30).

The egalitarian domestic nation determined by the original position underlies Rawls's global conception of justice. However, the process to conceive of the global principles of justice consists of two original positions. The first, as previously discussed, ensures the justly ordered, egalitarian domestic nation. The second stage is a second original position, where representatives of each reasonable and well-ordered, or legitimately decent hierarchical society, come to a mutually advantageous agreement for social cooperation - a global original position. Rawls defines a reasonable society of peoples as a liberal democratic nation.

In the global sphere, Rawls recognizes that not all countries subscribe to a liberal conception of justice. In accordance with liberal values, Rawls requires toleration for 
what he terms "decent hierarchical societies" (Rawls 1999, 62). These are societies that cannot be said to be liberal democratic nations; however, they are to be included in Rawls's Society of Peoples on the condition that they are non-aggressive, have a comprehensive, shared political conception of the good, prescribe basic human rights for all their citizens, and have enough of a basic institutional structure that the fundamental human rights are able to be enacted (Rawls 1999, 64).

The acceptance of decent, but non-liberal societies into the Society of Peoples has its foundation in Rawls's Political Liberalism (1993/2005). It is here where he describes his theory of political legitimacy. Legitimacy is the minimum standard Rawls requires in order to justify a nation's authority. It is a minimum in the sense that it is not necessarily just, as defined in A Theory of Justice (1971). Citizens within a nation will respect the authority of the laws if they are deemed legitimate. Likewise, outside nations will respect the sovereign authority of a nation if its laws are viewed as legitimate, and not attempt to intervene. This concept of legitimacy allows Rawls to construct a theory of global justice that can include more nations than simply the liberal societies with the domestic structure that he specifies in $A$ Theory of Justice. This allows him to ensure that decent hierarchical societies may be included under the principle of liberal toleration for alternative views of other nations. An example of a decent hierarchical society might be Cuba, who respects the rights of their citizens, however it is certainly not a democratic country. Thus, Rawls's Society of Peoples includes reasonable liberal, and decent hierarchical peoples, while excluding what he calls "outlaw states". These are nations that do not conform to the above listed criteria. This would include aggressive states, and 
states that do not pursue basic human rights for their citizens, a good example of this would be North Korea.

Rawls also prescribes a principle of assistance in dealing with a fourth type of society, what he calls "burdened societies". These are developing countries that lack the domestic policies and social institutions required to be well-ordered and economically prosperous. Rawls's duty of assistance is applied only to these societies. The aim is to assist these countries in establishing the basic institutional structures, as specified in Rawls's theory of justice. He states that decent societies have a moral obligation to assist burdened societies only up until the point where they can be seen to have become reasonably self-sufficient, even if still poverty-stricken. Here we can see a dramatic difference between Rawls' domestic and global views. Domestically, he favours principles of the redistribution of wealth in order to promote an egalitarian society. Globally, Rawls does not promote any such redistribution of wealth from affluent nations to the burdened societies. The duty of assistance only promotes the obligation to aid in the restructuring of political and social institutions. Rawls specifies a very clear target and cut-off point. At the point where the burdened society is able to begin its own road to prosperity, all aid to this country ceases. He claims that any country, whether wealthy or poor in resources, if well-ordered, can achieve prosperity (Rawls 1999, 108).

Rawls has two main arguments against global distributive schemes. The first argument claims that with the establishment of the duty of assistance already placed in his non-ideal theory, a distributive justice principle would be unnecessary (Rawls 1999, 117). The second argument is that distributive principles would have unacceptable results. One example of such unacceptable results would be that unlike the duty of 
assistance, distributive justice principles do not have a cut-off point. Also, he claims that distributive justice principles fail to distinguish between well-ordered, but impoverished nations from those that are burdened because they have either neglected their own development or failed to curb their population growth. Rawls claims that a distribution policy unfairly penalizes a nation for their sound domestic policies by redistributing their wealth to nations that he believes were irresponsible. Instead, Rawls argues that the duty of assistance is sufficient and more desirable. There is no obligation in his duty of assistance to see that individual citizens reach a minimum level of wealth or well-being, as this is the responsibility of their respective societies. The reason for the duty of assistance is to promote a well-ordered society in order to ensure peace and cooperation amongst the nations within the Society of Peoples. This clearly demonstrates the emphasis Rawls places on the nation being the point of moral concern at the global level.

\subsubsection{Pogge: The Global Resource Dividend and the Health Impact Fund}

As a central figure in the health rights literature, Thomas Pogge's World Poverty and Human Rights (2008), is a necessary addition to a literature review on this topic. Pogge conceives of a cosmopolitan global justice scheme that focuses on the well-being of individuals as citizens of a global world, with each individual having equal moral worth. Pogge's cosmopolitan conception originally consisted of an extension of John Rawls's famous difference principle into a global difference principle that redistributes the benefits and burdens between nations in order to establish background fairness on a global level. 
Pogge approach calls for a multilayered dispersal of authority, from a local level within nations, up to a supranational level. His aim is to distribute authority through an institutional structure that equally balances power at a local level, national level, and multiple institutional supranational levels. The reasoning behind the creation of multiple institutions at the supranational level is to limit the power of international bodies and stay away from the conception of a world government. It is at the international level that a global tax would be collected from wealthy nations and distributed to countries in severe poverty (Pogge 2008, 219). The cosmopolitan purpose for assisting countries whose citizens are considered to be the worst off is to ensure that the level of well-being of each individual is significantly improved.

Turning to the normative foundation of Pogge's theory of global justice, he argues that we have a strong negative duty to reduce the harms imposed on the poor by the global order. As the affluent benefit from the unjust economic system and benefit from the harming of the poor, we owe them compensation and therefore have a moral duty to assist. Pogge identifies two main sources of harm created or sustained by the global order. The first is what he calls the international resource privilege, which "includes the power to effect legally valid transfers of ownership rights in such resources [the natural resources of a country]" (Pogge 2004, 270). Such a privilege increases incentives to overthrow a legitimate government, allowing potentially corrupt individuals to legally sell off the country's natural resources for personal profit. Pogge also argues that resource privilege increases foreign incentives to bribe officials, therefore increasing corruption within developing countries (Pogge 2004, 270). These factors contribute to an 
overall destabilizing effect, which Pogge argues harms individuals who must live in these countries.

The second harm that Pogge identifies is the international borrowing privilege. This privilege given to those in power "includes the power to impose internationally valid legal obligations upon the country" (Pogge 2004, 271). He argues that this privilege allows destructive governments to borrow large amounts of money to enforce their own power, increasing the difficulty to eradicate corrupt or harmful governments. If they are finally removed, the borrowing privilege cripples the successor government with such a burden of debt that they are unable to do much beyond maintaining debt payments, thereby destabilizing the country further. Pogge also argues that the borrowing privilege increases coup incentives, with the borrowing privilege as a reward for anyone who might be able to seize power.

For Pogge, global justice is about offsetting an unjust institutional redistribution from the poor to the rich. His strategy for redistributing the global wealth is what he calls the Global Resource Dividend, a global tax on the consumption of resources. The tax is based on the premise that all persons in the world have an entitlement to a share in the profits produced by the use and sale of natural resources. The natural resources of the world are supposed to be here for the common good, and it is a morally arbitrary point that some people are born in resource rich countries, and some are not. Even within the same country, it should not be morally important that some people have the opportunity to profit enormously on the resources available within the geographical territory, while others are not. The Global Resource Dividend then, is put in place in order to tax wealthy consumers of resources (Pogge 2008, 215). 
The Global Resource Dividend attempts to correct the ways in which the current global economic scheme enables and encourages the exploitation of poor resource rich nations by either domestic or foreign parties. It is currently permissible for anyone holding power - whether democratically elected, or violently seized — to personally profit off of the resources. The Global Resource Dividend seeks to remedy this in two essential ways. The first is the obvious hope that a tax on the consumption of these resources would diminish the appeal of attempting to profit from a heavily taxed resource. The second way is that through the vertical dispersal of authority, the hope is that the Global Resource Dividend would allow for a more even flow of currency throughout the country. Also, Pogge insists that this process is to be transparent, which would ensure that other countries could sanction a nation that seemed to be taking advantage of the resource privilege, as information of the sales and profits would now be part of a decentralized global system (Pogge 2008, 214).

How the Global Resource Dividend is to address the borrowing privilege is slightly less obvious. Currently, when a nation requires a loan, its only recourse is to go to the International Monetary Fund, or sometimes the World Bank. The way the global system is currently set up is that a nation may get the requested loan from the IMF, however there are very stringent conditionalities that come along with this loan that must be followed by the borrowing country. The conditionalities often deal with issues such as privatizing natural resources within the country, increasing trade, opening up borders to allow for foreign multinationals. These are normally thought to be decisions that are within the domain of a nation's sovereign rights. So in effect, a borrowing country is often sacrificing a considerable amount of autonomy in exchange for the loan. 
The Global Resource Dividend addresses this issue by creating an alternative approach for receiving funds that can be used towards development goals. Although the Dividend gives some parameters in order to ensure the proper use of the funds, they are in no way as stringent as funds from the IMF, and do not infringe on the autonomy of a sovereign country. Similarly, the Global Resource Fund does not allow a corrupt government to come into power, squander international loan money, and leave the burden of the debt for their successors. Ideally, the funds would be set up and distributed in order to be used to the benefit of the people within the country; otherwise the funds would be cut off. This removes the incentive for people to seize power for their own personal profit, and to the detriment of their successor.

In order to change the unjust international institutions that prevent the poor from accessing urgent medicines that they need, Pogge focuses on the role of pharmaceutical companies and the World Trade Organization's TRIPS Agreement (The Agreement on Trade-Related Aspects of Intellectual Property Rights). TRIPS aids pharmaceutical companies in recouping their research and development costs when developing new medicines by ensuring a 20 year product patent. This blocks any competition from other medical manufacturers producing cheaper generic versions of the drug, ensuring all profits go to the pharmaceutical company that originally developed the new drug (Pogge 2012, 7).

The product patent also means the prices remain high, and often too expensive for the developing world to afford. Pogge's solution to this problem is the Health Impact Fund (HIF). With the HIF system, pharmaceutical companies would have the option to register new drugs, allowing them to be made available at the lowest possible cost. The 
incentive would be that in exchange for making the drug available, the pharmaceutical company would receive a payment based on the drug's global health impact over the first ten years. Therefore, essential medications would be accessible to those who previously could not afford them, and the pharmaceutical companies would still be able to recoup their research and development costs, ensuring the incentive for the creation of new and innovative drugs is maintained (Pogge 2012, 7).

A cosmopolitan approach is quite a common way to attempt to justify some degree of global minimal health rights. Pogge, as well as Mann, Farmer, and Buchanan have all proposed various conceptions of such a cosmopolitan view. A particularly interesting aspect of Wolff's work is that he attempts to distinguish his claims for a human right to health from cosmopolitanism.

\subsubsection{Sen and Nussbaum: The Capabilities Approach and Health Rights}

The capability approach attempts to refocus the goal of development from an emphasis on economic growth to a human-centered model that recognized the importance of social, economic and cultural rights. Although the capabilities approach was not included in my specific discussion of the human right to health approach, it is part of the literature that promotes social, economic and cultural rights. The capabilities approach also recognizes the importance of access to universal health.

The emphasis on human well-being redefines poverty as the deprivation of the capability to be or do whatever they have reason to value. The goal of promoting a model such as the capabilities approach is to protect and increase individual's capabilities, (such as education, health, political access, etc.) correcting the unequal 
opportunities, thereby allowing the freedom to function in a way the individual considers to be of value (Sen 1999, 75).

The capabilities approach employs two important concepts: functionings and capabilities. Functionings are the 'beings and doings' of an individual. For an example, the state of an individual being healthy would be considered a functioning. Capabilities are an individual's real opportunities or freedoms to achieve functionings they value (Sen 1999, 75). Opportunities of access to health care, education, and political participation would be examples of the substantive freedoms a person would need in order to achieve being healthy as the functioning they value, for example.

Originally pioneered by Amartya Sen, the capabilities approach has also been extensively developed by Martha Nussbaum. Her development of Sen's capabilities approach focuses on the essential capabilities that she believes would promote human flourishing. Although Sen does not list any specific capabilities, Nussbaum lists ten that she believes to be central:

1. Life

2. Bodily Health

3. Bodily Integrity

4. Senses, Imagination, and Thought

5. Emotions

6. Practical Reason

7. Affiliation

8. Other Species

9. Play

10. Control over One's Environment

a. Political

b. Material (Nussbaum 2006, 78) 
Both Sen and Nussbaum include health as an important capability. It is an essential freedom for people's well-being. In Sen's article, "Why and How is Health a Human Right" (2008), he discusses the importance of fulfilling all of the social determinants of health beyond just health care, such as nutrition, education, and increasing women's empowerment. Sen points out that when one's individual freedoms are deprived and a society is unequal, that this impacts health. He claims there are "political, social, economic, scientific, and cultural actions that we can take for advancing the cause of good health for all” (Sen 2008, 2010).

Currently, this is the common and accepted definition of the human right to health. It is most often stated as a positive right that encompasses all of the various social determinates of health. Health is no longer considered just to be access to health care. Access to much more extensive social institutions is necessary for ensuring the health of a population. Although not entirely relevant to the negative right to health focus of my paper, Sen and Nussbaum both contributed to important background information on poverty, development, and the importance of a complex view of the social determinants of health.

\subsection{Conclusion}

The literature review primarily attempted to provide a more complete discussion of the relevant background theories that inform the human right to health literature. The central question that both my paper and literature review aimed to address is whether or not we can provide a normative foundation for the human right to health. The human right to health draws on many diverse areas of thought. Therefore, a discussion of human 
rights theory and literature from various areas of political philosophy, bioethics, and international development are important elements of a thorough understanding of the central question I raise in my paper.

My key point is that the focus of the literature has primarily been on a positive right to health, when in fact we can provide a normative foundation to the human right to health if we look at it as a negative right. A thorough discussion of both negative and positive aspects of the right to health provides a more complete picture of the crucial elements in the debate over the foundations of the human right to health. A negative right to health can provide a normative foundation and this missing component is required for building a complete framework for a human right to health. 


\section{Bibliography}

Annas, G. J. 1993. "Detention of HIV-Positive Haitians at Guantanamo." The New England Journal of Medicine 329, no. 8 (August 19): 589-592.

Arras, J.D. and E.M. Fenton. 2009. "Bioethics and Human Rights: Access to HealthRelated Goods." Hastings Center Report 39, no. 5 (2009): 27-38.

Beitz, C. 2009. The Idea of Human Rights. New York: Oxford University Press.

Buchanan, A. E. 2009. Justice and Health Care: Selected Essays. New York: Oxford University Press.

Cranston, M. 1973. What Are Human Rights? New York: Taplinger Publishing.

Daniels, N. 2010. "Rights to Health Care and Distributive Justice: Programmatic Worries.” In Health Rights. Edited by M.J. Selgelid and T. Pogge. Farnham, Surrey, UK: Ashgate Publishing Limited.

—. 2008. Just Health: Meeting Health Needs Fairly. New York: Cambridge University Press.

. 2007. "Rescuing Universal Health Care.” Hastings Center Report (MarchApril): 3 .

- 1985. Just Health Care. New York: Cambridge University Press.

Edmundson, W. 2004. An Introduction to Rights. Cambridge: Cambridge University Press. 
Farmer, P. 2008 "Challenging Orthodoxies: The Road Ahead for Health and Human Rights." Health and Human Rights 10, no. 1, 5-19

- Pathologies of Power: Health, Human Rights, and the New War on the Poor. Berkeley and Los Angeles: University of California Press.

. 2004. "An Anthropology of Structural Violence." Current Anthropology 45, no. 3 (June): 305-325.

1999. Infections and Inequalities: The Modern Plagues. Berkeley and Los Angeles: University of California Press.

—. 1996. "Social Inequalities and Emerging Infectious Diseases." Perspectives 2, no. 4 (October-December).

Farmer, P. and J.Y. Kim. 1991. "Anthropology, Accountability, and the Prevention of AIDS.” The Journal of Sex Research 28, no. 2 (May): 203-221.

Farmer, P. and Nicole Gastineau. 2002. "Rethinking Health and Human Rights: Time for a Paradigm Shift.” Journal of Law, Medicine \& Ethics 3, 655-666

Hessler, K. 2010. "Exploring the Philosophical Foundations of the Human Rights Approach to International Public Health Ethics.” In Health Rights. Edited by M.J. Selgelid and T. Pogge. Farnham, Surrey, UK: Ashgate Publishing Limited.

Kidder, T. 2004. Mountains Beyond Mountains: The Quest of Dr. Paul Farmer: A Man Who Would Cure the World. New York: Random House. 
Locke, J. 1698/1995. Treatise of Civil Government and A Letter Concerning Toleration. Edited by C.L. Sherman. New York: Irvington.

Mann, J.M., S. Gruskin, M.A. Grodin and G.J. Annas. 1999. Health and Human Rights: A Reader. New York: Routledge.

Mann, J.M. and S. Burris. 1998. "Public Health and Human Rights." Human Rights 25, no. 4 (Fall): 2-5.

Mann, J. M. and D. Tarantola, "Responding to HIV/AIDS: A Historical Perspective." Health and Human Rights, Vol. 2, No. 4, HIV/AIDS and Human Rights. Part 1: The Roots of Vulnerability (1998), pp. 5-8.

Mann, J.M. 2010. “Medicine and Public Health, Ethics and Human Rights.” In Health Rights. Edited by M.J. Selgelid and T. Pogge. Farnham, Surrey, UK: Ashgate Publishing Limited.

_ 1998. "AIDS and Human Rights: Where Do We Go from Here?" Health and Human Rights 3, no. 1, 143-149.

Mill, J.S. 1869/2008. On Liberty. Edited by A.S. Kahan. Boston: Debford/St. Martins.

Nussbaum, M. 2006. Frontiers of Justice. Boston: Harvard University Press.

Nussbaum, M. 2011. "Capabilities, Entitlements, Rights: Supplementation and Critique." Journal of Human Development and Capabilities 12, no. 1 (February): 23-37. 
O’Neill, O. 2010. “The Dark Side of Human Rights.” In Health Rights. Edited by M.J. Selgelid and T. Pogge. Farnham, Surrey, UK: Ashgate Publishing Limited.

_ 2002. "Public Health or Clinical Ethics: Thinking beyond Borders." Ethics and International Affairs 16, no. 2, 35-45.

Pogge, T. W. 2012. "The Health Impact Fund: Enhancing Justice and Efficiency in Global Health." Journal of Human Development and Capabilities 13, no. 4 (November): 537-559.

- 2008. World Poverty and Human Rights, Second Edition. Cambridge, MA: Polity Press.

. 2004. "Eradicating Systemic Poverty: Brief for a Global Resource Dividend." In Social Justice. Edited by M. Clayton and A. Williams. Oxford: Blackwell.

Rawls, J. 1993/2005. Political Liberalism. New York: Columbia University Press.

- 1999. The Law of Peoples. Cambridge, MA: Harvard University Press.

_ 1971/2005. A Theory of Justice. Cambridge, MA: Belknap Press.

. 2001. Justice as Fairness. Cambridge, MA: Harvard University Press.

Sen, A. 2009. The Idea of Justice. Cambridge, MA: Belknap Press. 
—. 2010. "Why and How is Health a Human Right?" The Lancet 372, no. 9655 (December 13).

-1999. Development as Freedom. New York: Random House.

Shue, H. 1996. Basic Rights: Subsistence, Affluence and U.S. Foreign Policy. New Jersey: Princeton University Press.

—. 1988. “Mediating Duties.” Ethics 98, no. 4 (July): 687-704.

Sreenivasan, G. 2012. “A Human Right to Health? Some Inconclusive Scepticism.” The Aristotelian Society, Supplementary Volume 86, 239-265.

—. 2002. "International Justice and Health: A Proposal." Ethics \& International Affairs 16, no. 2, 81-90.

—. "Health Care and Equality of Opportunity." Hastings Center Report 37, no. 2 (March-April): 21-31.

Wolff, J. 2013. "Global Justice and Health: The Basis of the Global Health Duty.” In Global Justice and Bioethics. Edited by J. Millum and E.J. Emanuel. New York: Oxford University Press. 2012a. The Human Right to Health. New York: W.W. Norton \& Company. . 2012b. "The Demands of the Human Right to Health". The Aristotelian Society Supplementary Volume 86, 217-237. 
UN General Assembly. 1966. "International Covenant on Economic, Social and Cultural Rights.” United Nations Treaty Series 993 (16 December 1966): 3. http://www.refworld.org/docid/3ae6b36c0.html (accessed 13 July 2013).

—_. "International Covenant on Civil and Political Rights." United Nations Treaty Series 999 (16 December 1966): 171. http://www.refworld.org/docid/3ae6b3aa0.html (accessed 13 July 2013)

World Health Organization. 1946/1948. Preamble to the Constitution of the World Health Organization as adopted by the International Health Conference. New York, 19 June - 22 July 1946. Signed on 22 July 1946 by the representatives of 61 States (Official Records of the World Health Organization, no. 2, p. 100) and entered into force on 7 April 1948.

UN Committee on Economic, Social and Cultural Rights (CESCR). 2000. General Comment No. 14: The Right to the Highest Attainable Standard of Health (Art. 12 of the Covenant), 11 August 2000, E/C.12/2000/4. http://www.refworld.org/docid/4538838d0.html (accessed 1 August 2013)

World Medical Association. 1948. Declaration of Geneva. Adopted by the General Assembly of World Medical Association at Geneva Switzerland, September 1948.

World AIDS Institute. "History.” http://www.worldaidsinstitute.org (accessed 13 July 2013) 